\title{
Production OptimizATION IN Fractured GeOthermal Reservoirs By COUPLED \\ DisCRETE FRACTURE NETWORK MODELING
}

\author{
Quan Gan $^{1,2}$ and Derek Elsworth ${ }^{1}$
}

\begin{abstract}
In this work, a stimulation then heat production optimization strategy is presented for prototypical EGS geothermal reservoirs by comparing conventional stimulation-thenproduction scenarios against revised stimulation schedules. A generic reservoir is selected with an initial permeability in the range of $10^{-17}$ to $10^{-16} \mathrm{~m}^{2}$, fracture density of $\sim 0.09 \mathrm{~m}^{-1}$ and fractures oriented such that either none, one, or both sets of fractures are critically stressed. For a given reservoir with a pre-existing fracture network, two parallel manifolds are stimulated that are analogous to horizontal wells that allow a uniform sweep of fluids between the zones. The enhanced connectivity that develops between the injection zone and the production zone significantly enhances the heat sweep efficiency, while simultaneously increasing the fluid flux rate at the production well. For a $10 \mathrm{~m}$ deep section of reservoir the resulting electric power production reaches a maximum of 14.5 MWe and is maintained over 10 years yielding cumulative energy recoveries that are a factor of 1.9 higher than for standard stimulation. Sensitivity analyses for varied fracture orientations and stimulation directions reveal that the direction of such manifolds used in the stimulation should be aligned closely with the orientation of the major principal stress, in order to create the maximum connectivity. When the fractures are less prone to fail, the output electric power is reduced by a decrease in the fluid flux rate to the production well.
\end{abstract}

\footnotetext{
${ }^{1}$ Department of Energy and Mineral Engineering, EMS Energy Institute and G3 Center, Pennsylvania State University, University Park, Pennsylvania, USA

${ }^{2}$ Department of Petroleum Geology \& Geology, School of Geosciences, University of Aberdeen, UK
} 


\section{Introduction}

Enhanced geothermal reservoirs (EGS) have been shown to be a viable resource for the recovery of thermal energy. However, due to their intrinsic characteristics of low permeability and porosity they have been proved intractable in developing sufficient fluid throughput by stimulation. The principal challenge has been in developing adequate permeability in the reservoir that also retains sufficient heat transfer area [Tester et al., 2006].

Numerical simulation is an essential approach to investigate coupled multi-physics processes (Thermal-Hydraulic-Mechanical) and to better understand the fundamental mechanisms and feedbacks that occur in geothermal reservoirs. This is particularly important due to the intense pressure-sensitivity of fractures in the coupling of permeability and heat transfer area [Taron and Elsworth, 2009]. From previous studies, thermal quenching and resulting contractile strains may substantially unload the reservoir and increase both fracture aperture and permeability via creep or by induced seismicity

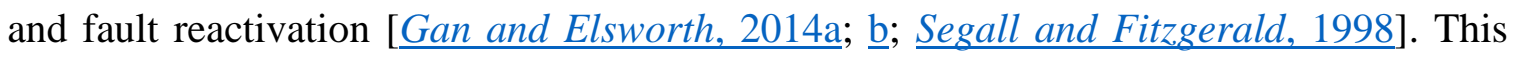
may occur close-in to the wellbore at early times and at later times in the far-field when larger features and faults may be affected [Elsworth et al., 2010; Taron and Elsworth, 2010a]. For discretely fractured rock masses, there are two major approaches to simulate the influence of randomly distributed fractures. One approach is to represent the fractured mass as a continuum where the aggregate response is represented [Taron and Elsworth, 2010b] and an alternative is a discontinuum approach [Ghassemi and Zhang, 2006; McClure and Horne, 2013; Min and Jing, 2003; Pine and Cundall, 1985] where individual fractures are discretized and their individual response followed. Continuum methods have the advantage of effectively simulating behavior at large (field) scale and for the long-term due to the lower computational requirements. The behavior of fractures is implicitly included in the equivalent constitutive models for both deformation and transport. The central effort in developing the equivalent continuum approach is the incorporation of crack tensor theory [Oda, 1986]. This is different in behavior from the application of discrete fracture network models (DFNs) where the behavior of individual fractures is explicitly represented in the macroscopic response. In previous work [Gan 
and Elsworth, 2016], an equivalent continuum T-H-M coupled simulator TF_FLAC ${ }^{3 \mathrm{D}}$ has been developed to investigate the evolution of stress-dependent fracture permeability in equivalent DFNs. The benefits of this continuum simulator are in mechanically representing the fractured mass by adopting a crack tensor, but also in simulating the heat and mass transport by advection and in the long term, albeit for continuum problems.

Strategies for optimizing production (high flowrate, high temperature and long duration) in geothermal reservoirs have been explored [Marcou, 1985; Akin et al., 2010; Pham, 2010] by identifying the impact of various parameters on thermal extraction, and in proposing strategies to enhance thermal power generation. The rate of heat energy production is defined by the effluent water temperature and flow rate from the production well. The ideal condition is to maintain both a high flux rate and high temperature for as long as possible, while simultaneously delaying thermal breakthrough to the production well. The reservoir volume (and temperature) is the key parameter that determines the cumulative magnitude of energy production over the entire reservoir life [Sanyal et al., 2005]. This reservoir volume is in turn influenced by the well separation distance as the reservoir volume scales with the "square" of this separation for a typical doublet injection-recovery system [Vörös et al., 2007]. In addition to reservoir volume and geometry, the characteristics of the injected fluid also exert some influence. Water density changes little in non-boiling systems but water viscosity may change by a factor of two or three with a change in temperature of 100-200 $\mathrm{C}$ and may therefore exert a direct impact on thermal production [Watanabe et al., 2000]. In addition to the ultimate recovery of thermal energy from the system, the rate of recovery is also important.

Dimensionless solutions are useful in defining the rate limiting processes and dependent properties for energy recovery. These simplified models capture the essence of the conductive heat supply to the convecting heat transfer fluid and define this process as the rate limiting step [Elsworth, 1989; 1990; Gringarten and Witherspoon, 1973; Gringarten et al., 1975; Pruess and Wu, 1993; Shaik et al., 2011]. The dimensionless parameter controlling the effectiveness of thermal recovery scales with the product of mass flow rate and fracture spacing to the second power [Gan and Elsworth, 2014b] thus defining 
the principal desire for small spacing between fractures in draining the heat from the fracture-bounded matrix blocks.

Circulating fluids at low rate per unit volume of the reservoir but to access small spacing between fractures is the principal requirement of a successful EGS system. The optimal scenario in production is to establish a uniform fluid-, and thereby thermal-sweep, of the reservoir. The divergent flow field close to the point-source injectors in doublet systems is not effective in providing a uniform sweep, but flow from parallel wells or from stimulated parallel wells offers a better prospect of establishing a uniform flow field. In the oil and gas industry, the drilling and stimulation of parallel, and typically horizontal, wells has been developed to considerable success for unconventional reservoirs, over the past decade. In this work, a new stimulation strategy is explored that comprises the development of two parallel and high permeability manifolds each as a separate injection zone and production zone. It is anticipated that this stimulation schedule will generate analogous results to the drilling of two horizontal wells and therefore in increasing the flow sweep efficiency from the injection zone towards the production zone. The influence of different stimulation strategy and slip potential in the heat transportation and followed heat generation are evaluated in this work.

\section{Model}

To implement an equivalent continuum model accommodating the fractured mass, the key constitutive relations require to be incorporated. These are the formulations for a crack tensor, a permeability tensor, and a model for stress-dependent fracture aperture.

\subsection{Crack tensor}

To represent the heterogeneous distribution of components of fractured rock in the simulation, the mechanical properties of fractures are characterized in tensor form based on the crack tensor theory proposed by Oda [ $\underline{O d a, 1986}]$. The theory is based on two basic assumptions: (1) individual cracks are characterized as tiny flaws in an elastic continuum; and (2) the cracks are represented as twin parallel fracture walls, connected by springs in both shear and normal deformation. By predefining the fracture properties, 
such as position, length, orientation, aperture, and stiffness, we implement crack tensor theory as a collection of disc-shaped fractures in a 3D system, and modify the distribution of modulus corresponding to the fractured rock and intact rock in each intersected element. Here the intact rock is assumed to be isotropic, the conventional elastic compliance tensor $M_{i j k l}$ for intact rock is formulated as a function of Poisson ratio, $v$, and the Young's modulus of the intact rock, $E$, as

$$
M_{i j k l}=\frac{(1+v) \delta_{i k} \delta_{j l}-v \delta_{i j} \delta_{k l}}{E}
$$

The compliance tensor $C_{i j k l}$ for the fractures are defined as a function of fracture normal stiffness $K_{n f}$, fracture shear stiffness $K_{s f}$, fracture diameter $D$, and components of crack tensors $F_{i j}, F_{i j k l}$ respectively .

$$
C_{i j k l}=\sum^{\text {fracnum }}\left[\left(\frac{1}{K_{n f} D}-\frac{1}{K_{s f} D}\right) F_{i j k l}+\frac{1}{4 K_{s f} D}\left(\delta_{i k} F_{j l}+\delta_{j k} F_{i l}+\delta_{i l} F_{j k}+\delta_{j l} F_{i k}\right)\right]
$$

where fracnum is the number of fractures truncated in an element block, $\delta_{i k}$ is the Kronecker's delta. The related basic components of crack tensor for each crack intersecting an element are defined $F_{i j}$ as below [Rutqvist et al., 2013],

$$
F_{i j}=\frac{1}{V_{e}} \frac{\pi}{4} D^{3} n_{i} n_{j}
$$

3

$$
\begin{aligned}
& F_{i j k l}=\frac{1}{V_{e}} \frac{\pi}{4} D^{3} n_{i} n_{j} n_{k} n_{l} \\
& P_{i j}=\frac{1}{V_{e}} \frac{\pi}{4} D^{2} b^{3} n_{i} n_{j}
\end{aligned}
$$


Where $F_{i j}, F_{i j k l}, P_{i j}$ are the basic crack tensors, $b$ is the aperture of the crack, $V_{e}$ is the element volume, and $n$ is the unit normal to each fracture. Therefore the formula for the total elastic compliance tensor $T_{i j k l}$ of the fractured rock can be expressed as,

$T_{i j k l}=C_{i j k l}+M_{i j k l}$

Combining equation 3-5 into equation 2, the equivalent fracture Young's modulus $E^{f}$ and Poisson ratio $v^{f}$ can be obtained as,

$$
E^{f}=\frac{1}{\frac{1}{E}+\left(\frac{1}{K_{n f}}-\frac{1}{K_{s f}}\right) \frac{1}{V_{e}} \frac{\pi}{4} D^{2} n_{1}^{4}+\frac{1}{K_{s f}} \frac{1}{V_{e}} \frac{\pi}{4} D^{2} n_{1}^{4}}
$$

7

$$
v^{f}=\frac{v}{E} E^{f}-\left(\frac{1}{K_{n f}}-\frac{1}{K_{s f}}\right) \frac{E^{f}}{V_{e}} \frac{\pi}{4} D^{2} n_{1}^{2} n_{2}^{2}
$$

8

Given the assumption that the properties of modulus are anisotropic, the equivalent bulk modulus $K$ and shear modulus $G$ for the fractured rock mass are formulated as below,

$$
K=\frac{1}{\frac{1}{K_{\text {int } a c t}}+\sum^{\text {fracnum }} \frac{V_{\text {ratio }}}{b}\left[\left(\frac{1}{K_{n f}}-\frac{1}{K_{s f}}\right)\left(1-n_{2}^{4}\right)+\frac{1}{K_{s f}} n_{1}^{2}\right]}
$$

9

$$
G=\frac{1}{\frac{1}{G_{\text {int act }}}+\sum^{\text {fracnum }} \frac{2 V_{\text {ratio }}}{b}\left[\left(\frac{1}{K_{n f}}-\frac{1}{K_{s f}}\right)\left(n_{1}^{4}-n_{1}^{2} n_{2}^{2}\right)+\frac{1}{K_{s f}} n_{1}^{2}\right]}
$$

where $K_{\text {intact }}$ is the bulk modulus of the intact rock, $G_{\text {intact }}$ is the shear modulus of the intact rock and $V_{\text {ratio }}$ is the volumetric ratio of the truncated fracture over the element volume. The stress-dependent evolution of fracture aperture will in turn update the equivalent modulus of the fractured rock masses. 


\subsection{Permeability tensor and aperture evolution}

Considering that the randomly distributed fractures may be intersected by multiple elements in the reservoir gridding, the directional fracture permeability is defined as a permeability tensor $k_{i j}$, which is able to represent the orientation of fractures and the explicit fracture volume intersecting any element block.

$k_{i j}=\sum^{\text {fracnum }} \frac{1}{12}\left(P_{k k} \delta_{i j}-P_{i j}\right)=\sum^{\text {fracnum }} \frac{1}{12}\left(\frac{V_{\text {ratio }}}{b_{\text {ini }}} b^{3} n_{k}^{2} \delta_{i j}-\frac{V_{\text {ratio }}}{b_{\text {ini }}} b^{3} n_{i} n_{j}\right)$

where $b_{i n i}$ is the initial aperture of fracture.

The effect of stress has a direct impact in changing the evolution of the fracture aperture, which will in turn change the compliance tensor in the simulation loop. Prior models for stress permeability coupling include hyperbolic models of aperture evolution [ $\underline{\text { Bandis et }}$ al., 1983; Barton and Choubey, 1977], which can describe the response of fracture aperture in normal closure under the influence of in-situ stress. The functionality of the hyperbolic model is mediated by the parameters of initial fracture normal stiffness $K_{n f}^{0}$, maximum closure of the fracture aperture $d_{n \max }$, initial aperture of the fracture, $b_{i n i}$, and the effective normal stress of the fracture $\sigma_{n}^{\prime}$, which is formulated as,

$$
\Delta d_{n}=\frac{d_{n \max }}{1+\frac{K_{n f}^{0} d_{n \max }}{\sigma_{n}^{\prime}}}
$$

A simplified Barton-Bandis hyperbolic model [Baghbanan and Jing, 2007] is adopted to model aperture evolution by introducing a new parameter - the critical normal stress $\sigma_{n c}$, which means that the normal compliance $C_{n}$ is reduced significantly when the aperture closure approaches the maximum closure. In order to simplify the hyperbolic solution it is assumed that the ratio of maximum normal closure $d_{n \max }$ relative to initial fracture aperture $b_{i n i}$ is constant at 0.9 . Given this assumption, the hyperbolic normal closure equation is transformed as, 
$\sigma_{n}^{\prime}=\frac{\sigma_{n c} \Delta d_{n}}{10\left(0.9 b_{i n i}-\Delta d_{n}\right)}$

and the normal stiffness is determined by the normal stress as,

$$
K_{n f}=\frac{\left(10 \sigma_{n}^{\prime}+\sigma_{n c}\right)^{2}}{9 \sigma_{n c} b_{i n i}}
$$

13

Where $\sigma_{n c}(M P a)=0.487 b_{i n i}(\mu m)+2.51$. This equation implies that the larger the initial aperture, the larger drawdown gradient of normal stress.

Fracture shear slip and related dilation are included in the simulator by lumping the influence into the response of the matrix rock being sheared. When the Coulomb failure criterion is reached, the shear displacement $u_{s}$ will generate shear dilation $b_{\text {dila }}$ in the normal direction according to the equation (Figure 1),

$b_{\text {dila }}=u_{s} \tan \phi_{d}$

\section{4}

where $\phi_{d}$ is the dilation angle. Figure 2 identifies the relationship between the shear stress and displacement due to normal dilation. When the shear stress reaches the critical magnitude $\tau_{s c}$, which is determined by the Coulomb failure criterion, shear failure triggers normal dilation (red line) to increase the fracture aperture as the shear displacement increases. To incorporate the weakening response for the onset of shear failure in fractured rock masses, the reduction of a linear slope gradient (black line) represents the significant reduction of fracture shear stiffness from $K_{s 1}$ to $K_{s 2}$ due to shear failure. The magnitude of the aperture increment added by shear dilation can be calculated as,

$b_{\text {dila }}=\frac{\tau-\tau_{s c}}{K_{s}} \tan \phi_{d}$ 


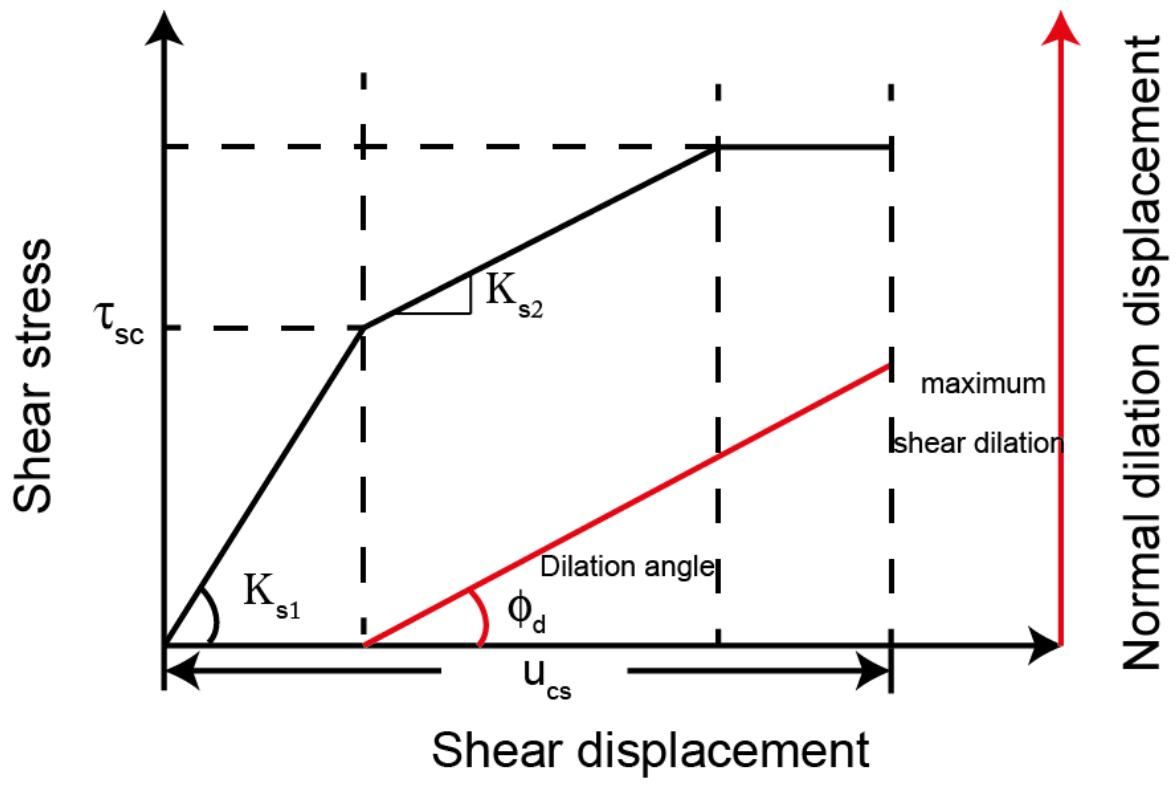

Figure 1 Fracture normal dilation displacement evolution induced from the shear slip in fracture.

When the fluid pressure in the fracture exceeds the normal stress across the fracture, the two walls of the fracture are separated and the effective normal stress is zero [ $\underline{\text { Crouch } \text { and }}$ Starfield, 1991] since $P_{f}=\sigma_{n}$.

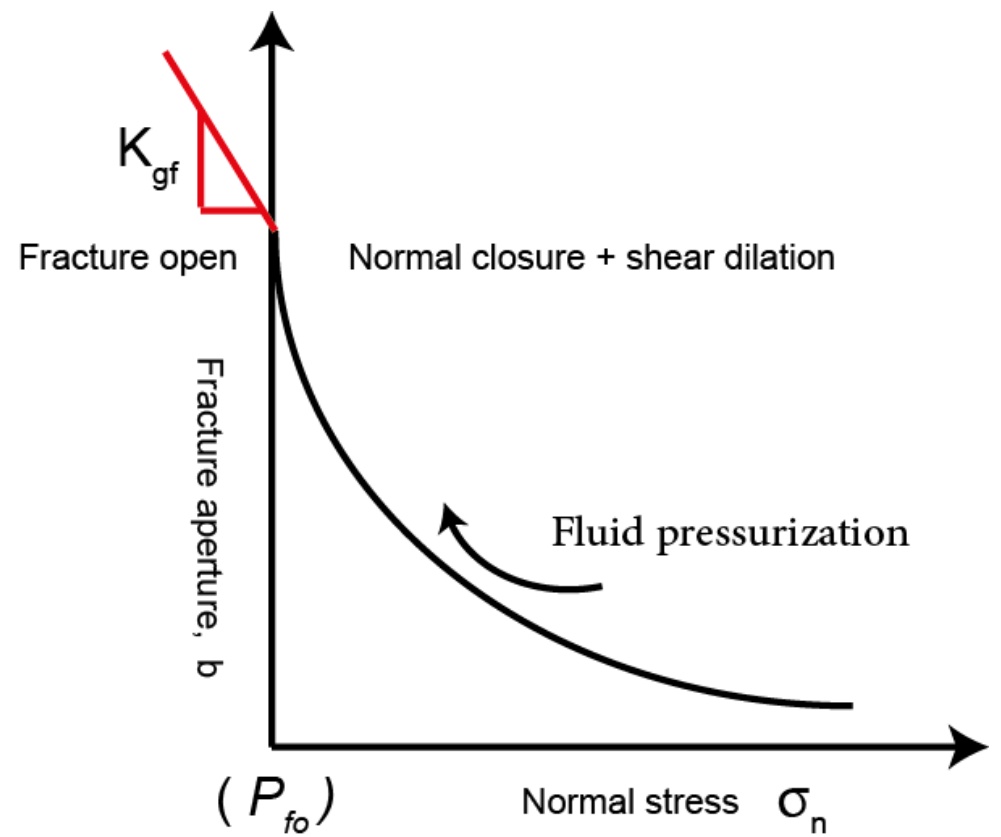

Figure 2 Fracture aperture evolution under different normal stress state. 
Figure 2 represents the constitutive relation for fracture aperture evolution applied in this model. The curve to the right is the regime under normal closure and shear dilation. However, as soon as the fluid pressure reaches the critical magnitude $P_{f_{0}}$ where effective stress is zero (left side in Figure 2), a geometrical stiffness $K_{g f}$ for a penny-shaped fracture is employed to calculate the induced normal opening displacement when the two walls are under tension. The normal opening displacement is linear with an increment of fluid pressure $\left(P_{f}-P_{f 0}\right)$. This geometrical stiffness $K_{s}^{\text {rock }}$ [Dieterich, 1992], although small, is much larger than that of the fracture in shear and is defined as,

$$
K_{s}^{r o c k}=\eta \frac{G}{r}=\frac{7 \pi}{24} \frac{G}{r}
$$

16

where $\mathrm{G}$ is the shear modulus of the intact rock, $D$ is the fracture half length, and $\eta$ is a geometrical factor which depends on the crack geometry and assumptions related to slip on the patch [Dieterich, 1992]. In this study, $\eta$ is defined to represent a circular crack and is given as $\frac{7 \pi}{24}$. Therefore the equation for the fracture opening displacement $b_{\text {open }}$ is formulated as below,

$$
b_{\text {open }}=\frac{P_{f}-P_{f 0}}{K_{g f}}=\frac{P_{f}-P_{f 0}}{10 K_{s}^{\text {rock }}}=\frac{\left(P_{f}-P_{f 0}\right)}{10 \times \frac{7 \pi}{24} \frac{G}{r}}
$$

\section{7}

To summarize, equations 11,15 , and 17 , represent the relations for considering stressdependent aperture change including normal closure, shear dilation, and fracture opening is obtained as,

$$
b=b_{i n i}-\frac{9 b_{i n i} \sigma_{n}^{\prime}}{\sigma_{n c}+10 \sigma_{n}^{\prime}}+\frac{\tau-\tau_{s c}}{K_{s}} \tan \phi_{d}+\frac{\left(P_{f}-P_{f 0}\right)}{10 \times \frac{7 \pi}{24} \frac{G}{r}}
$$


where $b_{i n i}$ is the initial aperture of the fracture, $b_{\text {normal }}$ is the reduction of aperture due to the normal closure, $\sigma_{n}$ is the effective normal stress of the fracture, $\sigma_{n c}$ is the critical normal stress, $\tau_{s c}$ is the critical shear stress where shear failure happens.

\subsection{Reservoir Model}

We explore various stimulation strategies to determine the influence of stimulation direction relative to the fracture orientations on both the magnitude and longevity of thermal recovery rates, for a given reservoir with a defined pre-existing fracture network. For these reservoirs, the fracture permeability of the network evolves subject to the influence of the change in stress state, including normal closure, shear dilation, and the potential for fracture walls to lose contact. Thermal effect exerts a strong effect in changing the fracture normal stress with a concomitant influence on both fracture-normal dilation and on shear-slip-induced dilation and ultimately modifying permeability. This work investigates the influence of an initial stimulation followed by a production phase throughout which permeability evolves in response to the evolving effective stress regime. In particular, we explore the potential that the stimulation may develop hydraulicallyinterconnected manifolds along the axis of a supposed horizontal well (E-W direction) that in turn may be used to develop a uniform flow field across the reservoir (in the N-S direction) - to a second parallel manifold also aligned in the E-W direction (Figure 3a). Another stimulation strategy is to develop permeable manifolds in the N-S direction by connecting the drilling wells in N-S direction (Figure 3b). These two behaviors will be different due to the directional characteristics of both the stress regime and the topology of the fracture network that is overprinted on the well pattern. The influence of fracture stimulation direction is illustrated through a comparison of the different development scenarios. 


\section{$\mathrm{E}-\mathrm{W}$ stimulation}

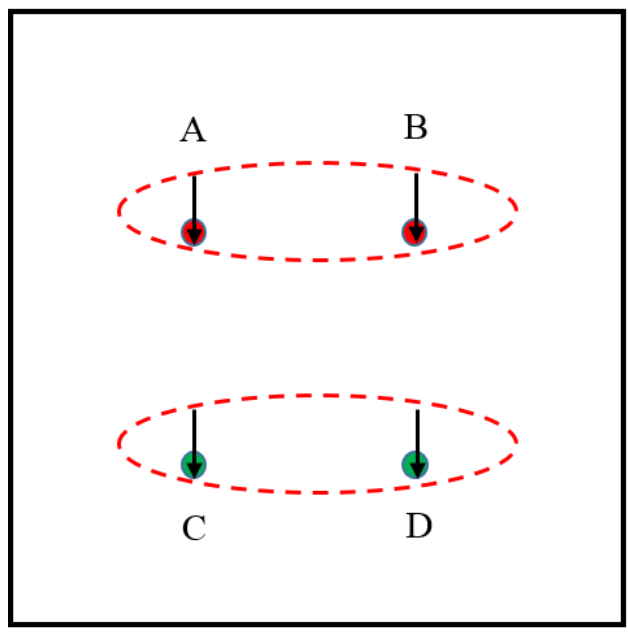

(a)

\section{$\mathrm{N}-\mathrm{S}$ stimulation}

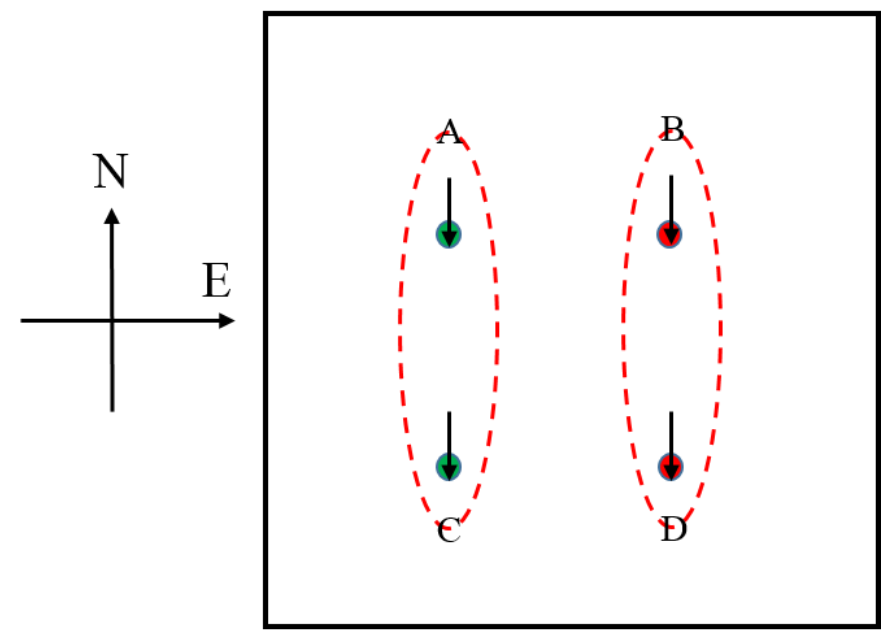

(b)

Figure 3 Hydraulically-interconnected manifolds creation from different stimulation strategies.

A reservoir containing two sets of fractures is created using the equivalent continuum simulator TF_FLAC ${ }^{3 \mathrm{D}}$. Figure 4a shows one scenario of the resulting fracture network in a reservoir $1500 \mathrm{~m} \times 1500 \mathrm{~m} \times 10 \mathrm{~m}$. The number of grid blocks are created at $60 \times 60 \times 1$, therefore the size for each block is uniform at $25 \mathrm{~m} \times 25 \mathrm{~m} \times 1 \mathrm{~m}$. The initial pressure distribution is uniform at $10 \mathrm{MPa}$, and the initial homogenous rock temperature is $250 \mathrm{C}$. The minor principal stress is imposed at $19.5 \mathrm{MPa}$ in the N-S direction, while the major principal stress is $30 \mathrm{MPa}$ in the $\mathrm{E}-\mathrm{W}$ direction. The geometries of the pre-existing fracture networks are presented in Figure 3. It is assumed that the networks are consisted by two sets of fractures. There are 1000 fractures for each set. The initial permeability of the fracture network is in the order of $10^{-17}$ to $10^{-16} \mathrm{~m}^{2}$. The fractures in each fracture set are oriented at a uniform angle. Two fracture geometries are chosen. The first is where both sets of fractures are favorably oriented for slip and strike $045^{\circ}$ and $120^{\circ}$ clockwise from the North (Figure 4a) [Odling, et al, 1999; Riahi and Damjanac, 2013]. The second geometry is where one set is less favorably aligned for slip where the fractures strike $020^{\circ}$ and $135^{\circ}$ with respect to the North direction (Figure $4 \mathrm{~b}$ ). The impact of fracture orientations and failure potential on thermal transport and heat recovery is assessed through the comparison between these two fracture geometries. 
The length of fractures follows a lognormal distribution with a mean length of $80 \mathrm{~m}$ (Figure 4) [de Dreuzy et al., 2001]. A power law is implemented to correlate fracture trace length $l$ with the initial fracture aperture $b_{i}$ [Olson, 2003] as (Figure 5),

$b_{i}=1.25 \times 10^{-5} * l^{0.8}$

19

The fracture density $\rho_{f}(1 / m)$ is expressed as the ratio of fracture surface area to the volume of matrix rock, as,

$\rho_{f}=\frac{\sum A_{f}^{i}}{V_{r o c k}}$

where $A_{f}^{i}$ is the surface area of the $\mathrm{i}_{\text {th }}$ fracture, and $V_{\text {rock }}$ is the total rock volume. The fracture density in this particular case is equal to $\sim 0.09 \mathrm{~m}^{-1}$. 


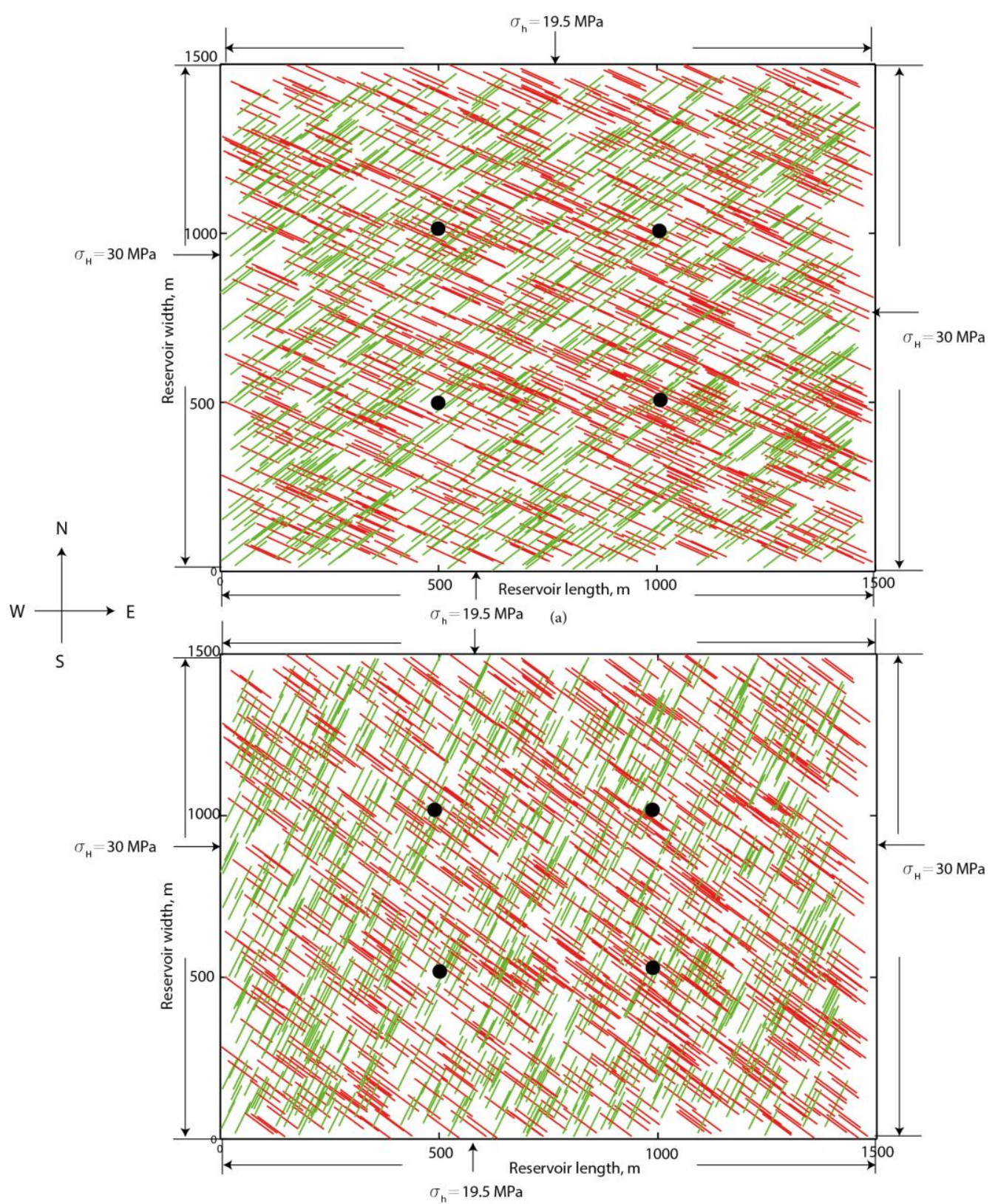

(b)

Figure 4. (a) Discrete fracture network distribution with orientations striking 045 and 120 degrees with respect to the North, (b) and a second discrete fracture network distribution with orientations at 020 and 135 degrees with respect to the North. These two orientations are chosen to evaluate the impact of fracture network geometry on fluid flow and heat transport. 


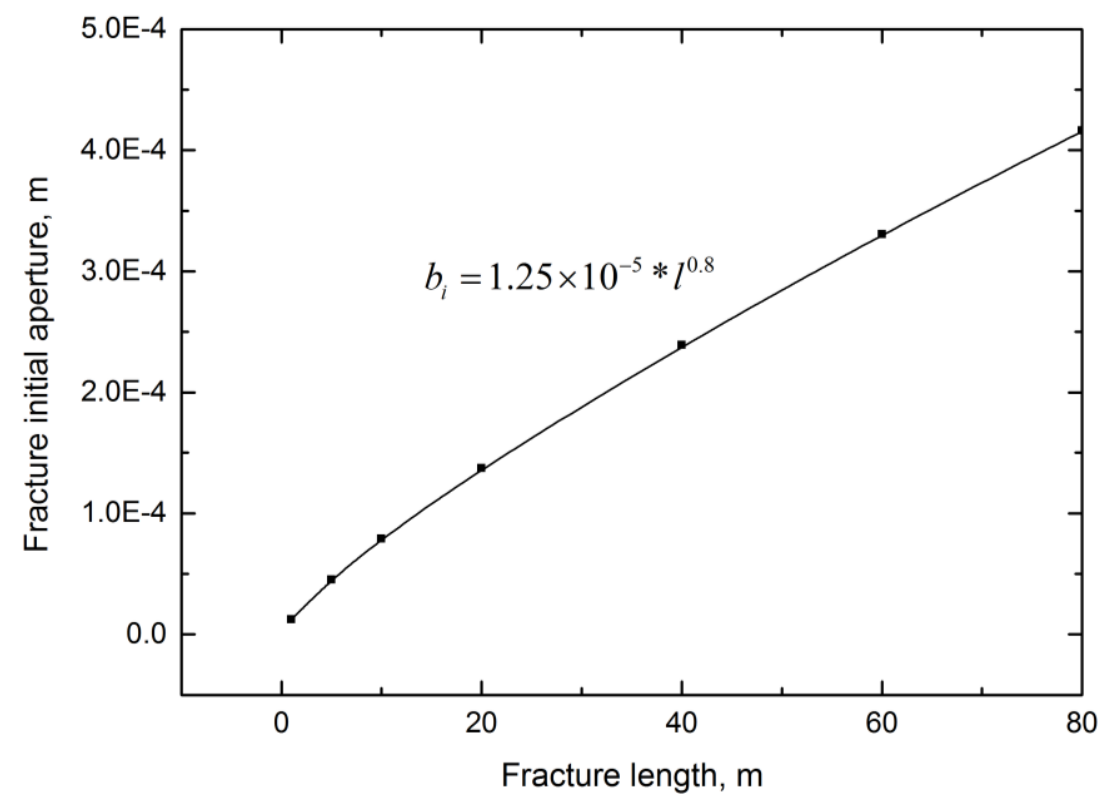

Figure 5 Nonlinear power law relationship between the fracture length and fracture initial aperture.

Table 1. Rock and fracture properties used in the simulation [McTigue 1990].

\begin{tabular}{lc}
\hline Parameter (unit) & Magnitude \\
\hline Shear modulus, $\mathrm{G}(\mathrm{GPa})$ & 15 \\
Poisson's ratio, $v$ & 0.25 \\
Undrained Poisson's ratio, $\nu_{\text {undrain }}$ & 0.33 \\
Matrix permeability, $k_{m}\left(\mathrm{~m}^{2}\right)$ & $1.0 \times 10^{-18}$ \\
Fracture permeability, $k_{f}\left(\mathrm{~m}^{2}\right)$ & $10^{-17} \sim 10^{-16}$ \\
Matrix porosity, $\phi_{m}$ & 0.01 \\
Fracture porosity, $\phi_{f}$ & 0.1 \\
Biot coefficient, $\alpha$ & 0.88 \\
Water viscosity, $\mu,(\mathrm{Pa} \mathrm{s})$ & $3.547 \times 10^{-4}$ \\
Fluid compressibility, $\left(\mathrm{MPa}^{-1}\right)$ & $4.2 \times 10^{-4}$ \\
Thermal expansion coefficient of solid, $\alpha_{s},\left(\mathrm{~K}^{-1}\right)$ & $2.4 \times 10^{-5}$ \\
Thermal diffusivity of intact porous rock, $\mathrm{c}^{T},\left(\mathrm{~m}^{2} / \mathrm{s}\right)$ & $1.1 \times 10^{-6}$ \\
Heat capacity of fluid, $c_{w}\left(\mathrm{Jkg}^{-1} \mathrm{~K}^{-1}\right)$ & 4200 \\
\hline
\end{tabular}




\begin{tabular}{lc}
\hline Initial reservoir temperature, $T_{0},(\mathrm{~K})$ & 523 \\
Injection water temperature, $T_{i n j},(\mathrm{~K})$ & 323 \\
Initial joint normal stiffness, $k_{n},(\mathrm{GPa} / \mathrm{m})$ & 0.5 \\
Initial joint shear stiffness, $k_{s},(\mathrm{GPa} / \mathrm{m})$ & 50 \\
In-situ stress $(\mathrm{MPa})-\mathrm{E}-\mathrm{W}$ direction & 30 \\
In-situ stress $(M P a)-\mathrm{N}-\mathrm{S}$ direction & 19.5 \\
Initial reservoir pore pressure, $p_{0},(\mathrm{MPa})$ & 10 \\
Injection pressure, $p_{i n j},(M P a)$ & 15 \\
Fracture friction angle, $($ degrees $)$ & $35^{\circ}$ \\
Fracture dilation angle, $(\mathrm{degrees})$ & $3^{\circ}$ \\
Fracture cohesion, $C,(M P a)$ & 0 \\
Production pressure, $p_{p r o},(M P a)$ & 7 \\
\hline
\end{tabular}

\subsection{Stimulation - Production Case}

The influence of stimulation strategy is investigated by stimulating the reservoir in multiple different modalities. Figure 6 schematically shows the two predefined stimulation scenarios: the first produces two parallel manifolds in the E-W direction (Figure 6a), while a second alternative is to develop two parallel manifolds in the N-S direction (Figure 6b) respectively. These parallel manifolds (Figure 6a) are then used to promote a uniform flow regime across the reservoir. In this reservoir, there are four potential well sites at points A $(500,1000)$, B (1000, 1000), C (500, 500), D (1000, 500). In terms of stimulation in the E-W direction, only the two injection wells at $\mathrm{A}$ and $\mathrm{B}$ are initially stimulated at $20 \mathrm{~kg} / \mathrm{s}$ for 10 hours [Darnet et al. 2006]. Then the other two wells at $\mathrm{C}$ and $\mathrm{D}$ are stimulated, again at $20 \mathrm{~kg} / \mathrm{s}$ for 10 hours, while the injection wells at $\mathrm{A}$ and $\mathrm{B}$ are shut-in. The developed manifolds result in enhancing the fracture permeability horizontally between A-and-B and C-and-D, separately. Similarly, the N-S stimulation scenario is designed to first develop a manifold between injection wells at B-D with the same constant injection rate of $20 \mathrm{~kg} / \mathrm{s}$ for 10 hours, and then to switch to inject at same rate into $\mathrm{A}$ and $\mathrm{C}$ for 10 hours (Figure $6 \mathrm{~b}$ ). Then the eventual production scenario is designed to place two injectors at wells $\mathrm{C}$ and $\mathrm{D}$ at a constant pressure of $15 \mathrm{MPa}$, while 
the producers are located at A and B points at a constant pressure of $7 \mathrm{MPa}$ (Figure 6c). In either instance, the pressure drop across the reservoir is $8 \mathrm{MPa}$.

Table 2. Case studies designed in the study for different stimulation - production scenarios

\begin{tabular}{|c|c|c|c|}
\hline Case No. & $\begin{array}{c}\text { Stimulation } \\
\text { Scenario }\end{array}$ & $\begin{array}{c}\text { Fracture Orientation, } \\
\text { degree }\end{array}$ & $\begin{array}{c}\text { Fracture Friction Angle, } \\
\text { degree }\end{array}$ \\
\hline 1 & Stimulation (E-W) & $135-020$ & $35-35$ \\
\hline 2 & Stimulation (N-S) & $135-020$ & $35-35$ \\
\hline 3 & No Stimulation & $135-020$ & $35-35$ \\
\hline 4 & Stimulation (E-W) & $045-120$ & $35-35$ \\
\hline 5 & Stimulation (E-W) & $045-120$ & $35-75$ \\
\hline
\end{tabular}

Table 2 indicates the separate cases explored in this study. The fracture properties in Case 2 and Case 3 are identical with those in Case 1, however there is no initial stimulation performed in Case 3. The influence of stimulation is revealed by comparing Case 2, 3 against Case 1. The results in Case 4 with a different fracture orientation of 045 -and120 degrees illustrates the impact of fracture orientation on heat recovery, as the fracture aperture is stress sensitive due to the variation of fracture orientation. Case 5 is implemented to examine the influence of fracture failure potential in the production of heat from the reservoir. In this, a 75 degree friction angle is set for the secondary set of fractures in Case 5 to evaluate the influence where one set of fractures has less potential to slip. 


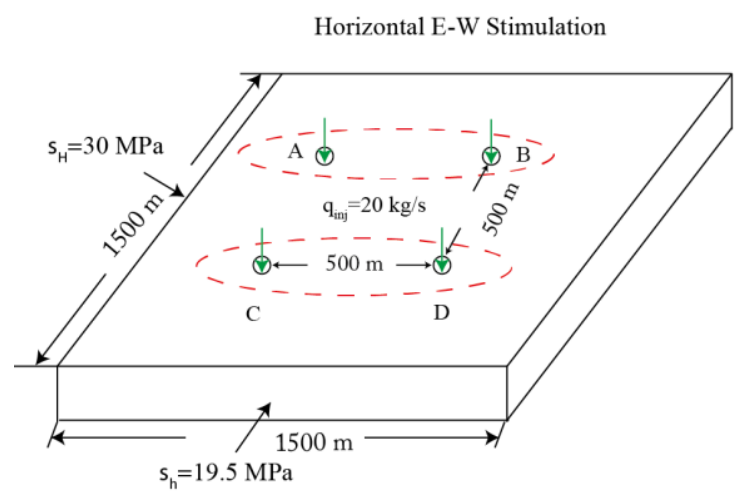

(a)

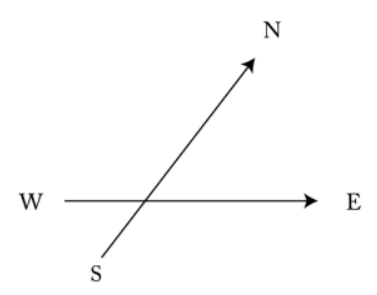

Horizontal N-S Stimulation

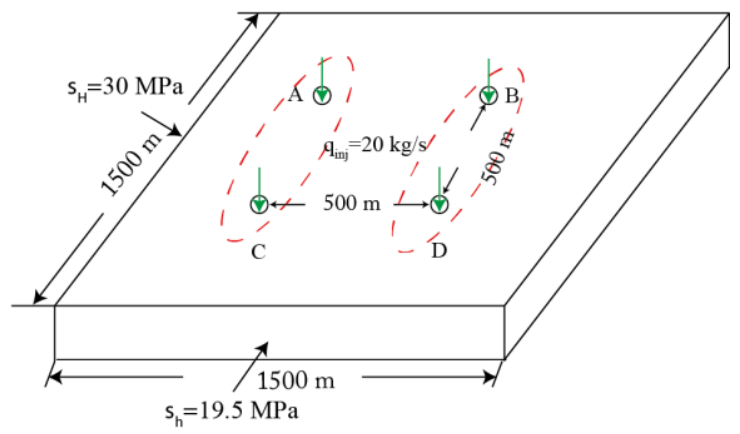

(b)

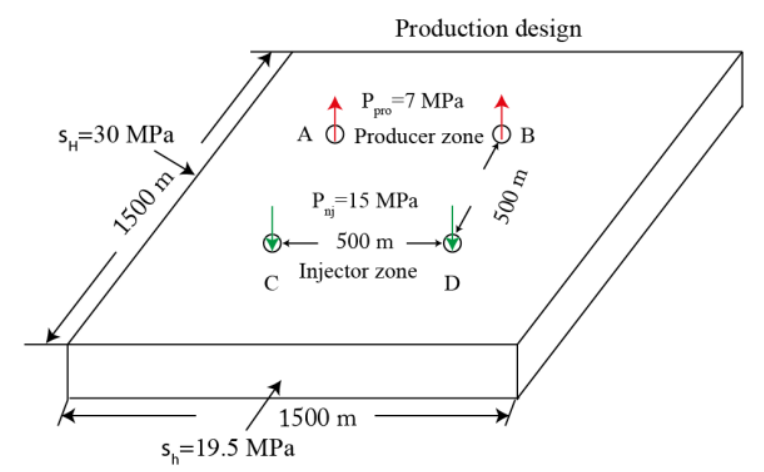

(c)

Figure 6. Schematic of injection and production design, (a) stimulate the injection and production zones separately at $20 \mathrm{~kg} / \mathrm{s}$ in the E-W direction, (b) stimulate the reservoir in the N-S direction at $20 \mathrm{~kg} / \mathrm{s}$, (c) the eventual production design including two injection wells at locations $\mathrm{C}$ and $\mathrm{D}$ points at constant pressure of

$15 \mathrm{MPa}$, and the two production wells at $\mathrm{A}$ and $\mathrm{B}$ at a constant pressure $7 \mathrm{MPa}-$ for a pressure drop of 8

MPa.

\section{Results Discussion}

The magnitude of permeability evolution and the resulting influence on heat energy extraction are the primary variables in this study. The potential optimization strategy is explored by investigating the relationship between the permeability enhancement due to stimulation and the resulting efficiency of heat recovery.

Figure 7 shows a comparison of the evolution in fracture permeability for the various fracture properties and stimulation scenarios. Figures 7(a) and 7(b) represent the initial fracture permeability distribution for the fractures oriented at $045-120$ degrees and 020 - 135 degrees with respect to the North direction. The initial equivalent permeability of the fracture network is in the range of $10^{-17}$ to $10^{-16} \mathrm{~m}^{2}$. The directional fracture 
permeability is defined as a permeability tensor $k_{i j}$ accommodating the orientation of the fractures and the explicit fracture volume intersecting an element block as

$k_{i j}=\sum^{n f} \frac{1}{12}\left(\frac{V_{\text {ratio }}}{b_{\text {ini }}} b^{3} n_{k}^{2} \delta_{i j}-\frac{V_{\text {ratio }}}{b_{i n i}} b^{3} n_{i} n_{j}\right)$

where $b_{i n i}$ is the initial aperture of the fracture, $n$ is the unit normal to each fracture, $V_{\text {ratio }}$ is the volumetric ratio of the truncated fracture volume over the element volume [Rutqvist, et al., 2013].

The fracture permeability distribution following the initial E-W stimulation for the fractures oriented at $045-120$ degrees is presented in Figure 7(c). The two black dashed circles show the development of two permeable horizontal manifolds created in the northern and southern portions of the reservoir. The fracture permeability is significantly improved by $\sim 3$ orders magnitude following the stimulation, due to an effective increase in fracture aperture of the order of 10 times during the extensile loading. Since the fractures are oriented close to the E-W direction, the fracture permeability along this direction of stimulation is significantly enhanced (E-W direction).

The dashed black circle in Figure 7(d) shows the principal area where the fracture permeability is enhanced following stimulation for fracture orientations at $020-135$ degrees. The red area representing the permeability-enhanced regime is oriented at an azimuth of $\sim 060$ degree. Moreover, the area of highest permeability in red (Figure 7(d)) is smaller than that red area in Figure 7(c), since the fractures (020 - 135 degrees) are not favorably oriented along the direction of stimulation (E-W). 


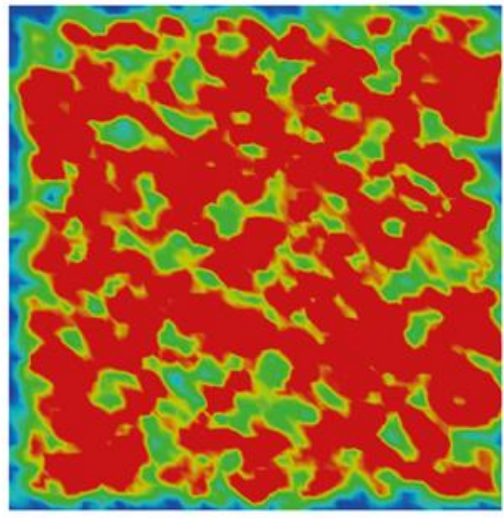

(a)

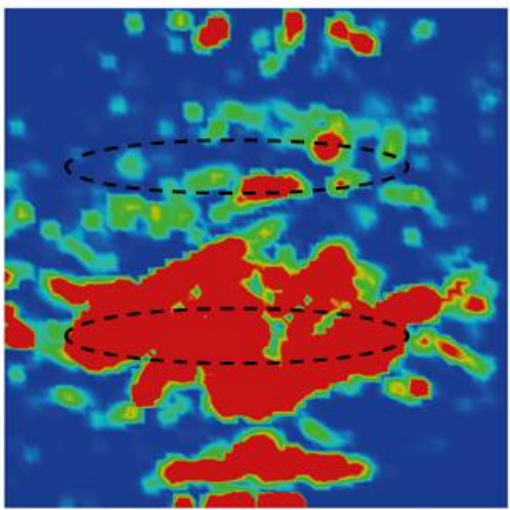

(c)
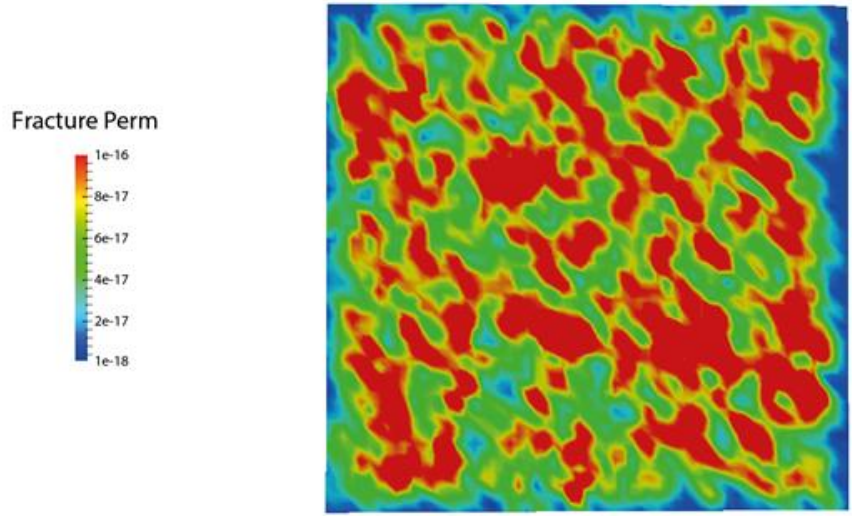

(b)

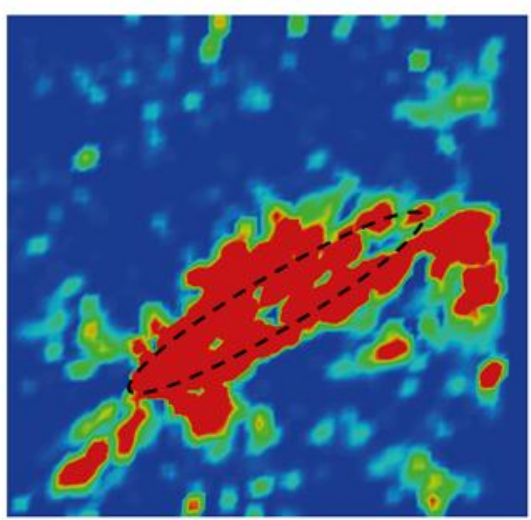

(d)

Figure 7. Contour plots of equivalent rock mass permeability evolution, (a) initial fracture permeability distribution for fractures oriented 045 - 120, (b) initial fracture permeability distribution for the scenario of fractures oriented $020-135$, (c) development of two interconnected manifolds after the E-W stimulation for fractures oriented $045-120$, (d) fracture permeability distribution after the E-W stimulation for fractures oriented $020-135$ degrees.

The corresponding cases for the generation of power from the various stimulations are presented in Figure 8. The magnitude of instantaneous electric power generation $W_{h}$ is calculated as a product of flow rate and the enthalpy of the water as [Pruess, 2006],

$$
W_{h}=\sum_{i=1}^{i=2} \alpha q_{p r o}^{i}\left(h_{p r o}-h_{i n j}\right)
$$

where $\alpha$ is the heat utilization efficiency, assumed to be 0.45 in this calculation [Sanyal and Butler, 2005]. $h_{p r o}$ is the water enthalpy at the production well with the highest 
enthalpy in this work equals to $1.08 \times 10^{6} j / \mathrm{kg}(250 \mathrm{C}), h_{i n j}$ is the enthalpy of the injected cold water, which is equal to $2.0 \times 10^{5} j / \mathrm{kg}$, and $q_{p r o}^{i}$ is the flow rate in the $\mathrm{i}_{\text {th }}$ production well $(\mathrm{kg} / \mathrm{s})$.

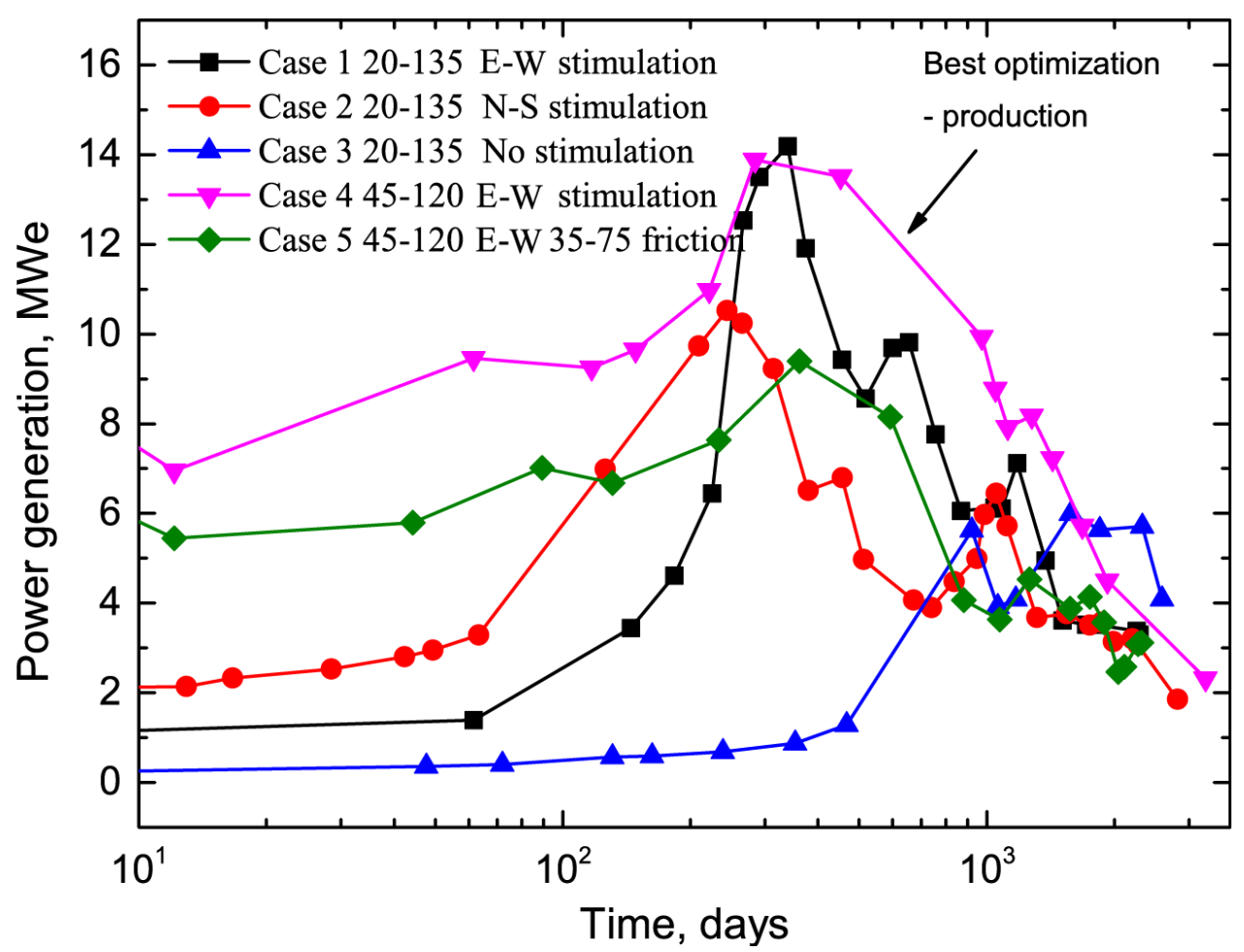

Figure 8. Comparison of total electric power generation from two production wells between all five cases.

The magenta curve (Case 4) is for fractures oriented 045 - 120 degrees with E-W stimulation and this returns the highest electric power generation. Case 3 shown by the blue curve for fractures oriented $020-$ 135 degrees but without stimulation indicates the lowest power generation. 

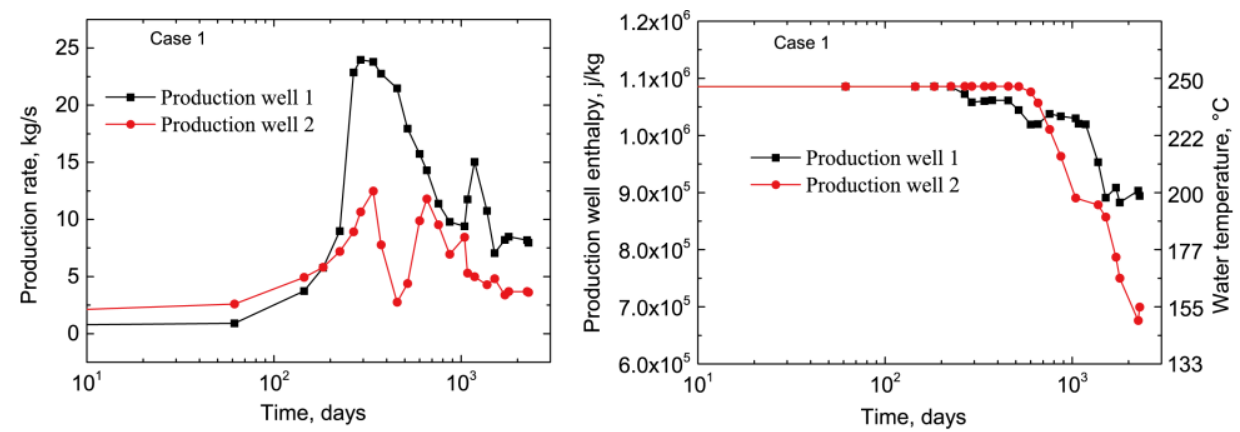

(a)
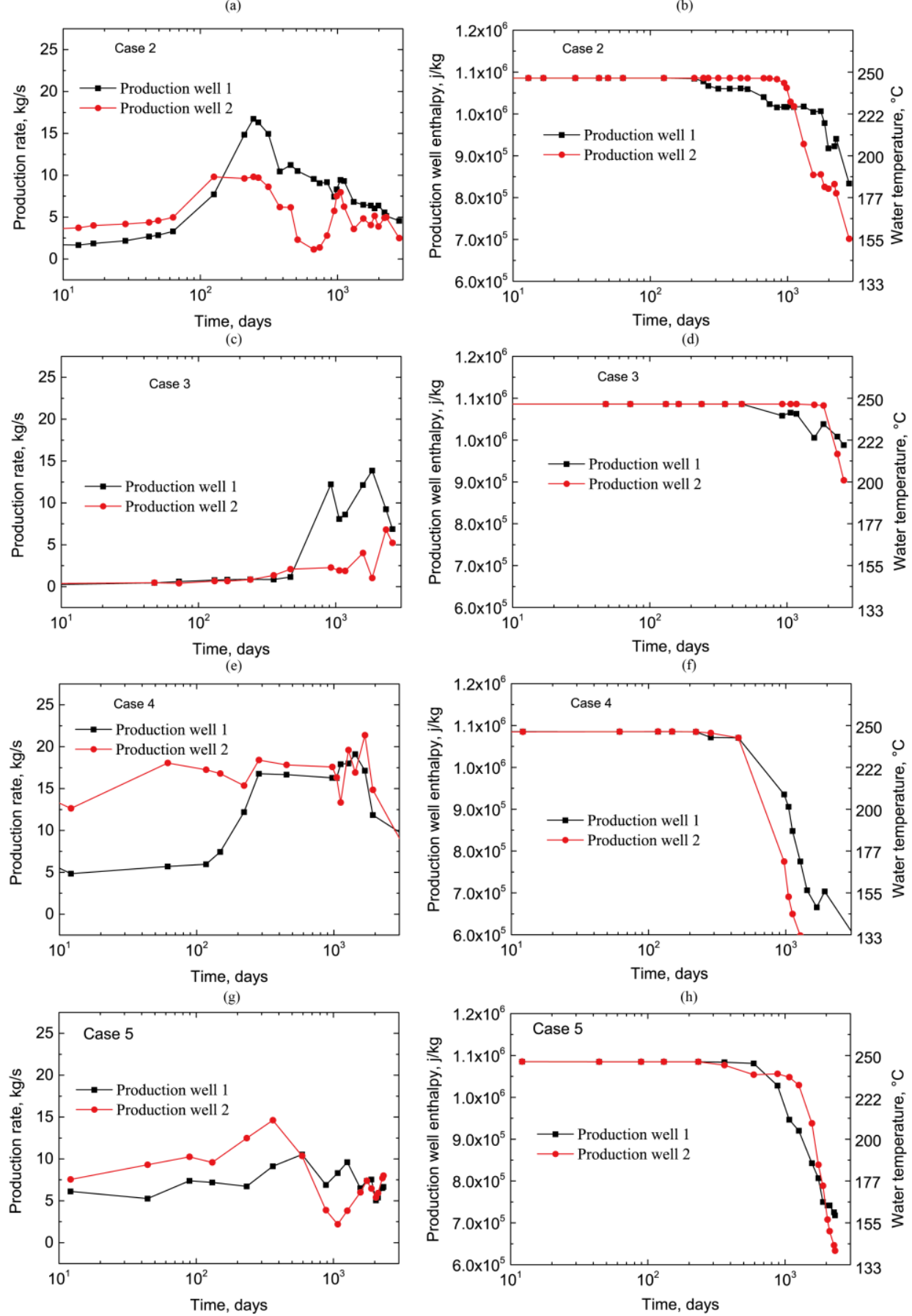

(i)

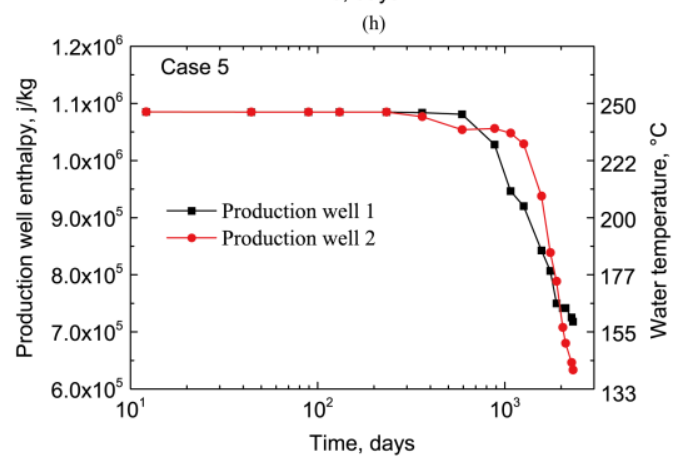

(j) 
Figure 9. Evolution of flow rate and water temperature (enthalpy) in the two production wells. Plots in the left column (a, c, e, g, i) represent the flow rate evolution in the two production wells for the five cases (15), plots in the right column $(b, d, f, h, j)$ represent the evolution of water temperature in the two production wells respectively.

The results indicate that Case 4 (fractures oriented at 045 - 120 degrees) returns the highest power output, sustaining the highest power generation within 10 years. The peak magnitude of generated power from the two production wells is maintained around 14 MWe. The evolution of the flow rate and corresponding water temperature from Case 4 suggests that the horizontal E-W stimulation is the most effective in maintaining both a high production flow rate and elevated temperature of outflow water at the highest level (Figure $9(\mathrm{~g})$ and $(\mathrm{h})$ ).

The predefined high friction angle of 75 degrees for the second fracture network in Case 5 is intended to lock this fracture set as resistant to failure. The corresponding results for power generation indicate the reduced potential of shear failure that impairs the magnitude of power generation by decreasing the fracture permeability.

The lowest intensity of power generation (Figure 8) represents Case 5 (no stimulation performed). Even though the temperature at the production well is maintained with the least thermal drawdown (Figure 9f), the flow rate in the production wells are small and uneconomical for power generation. Therefore this indicates that horizontal permeable manifolds are potentially both efficient and necessary for economical heat extraction from these geothermal reservoirs.

The distributions of rock temperature are presented in Figure 10 for the previous five cases at the same elapsed time of $t=6.34$ years. Examining the temperature distribution in the reservoir yields some impression of the best performance of heat production with the best heat sweep efficiency. Figures 10 (a) and (b) show the distributions of rock temperature for fractures orientated 020 - 135 degrees with stimulation along in the E-W and then the N-S directions, separately. The cooled volume in Figure 10(b) is slightly smaller than that in Figure 10(a). The distribution of rock temperature in Figure 10(a) and (b) indicate a sharper thermal front propagating from injector to producer. The cooling 
regime for the case without stimulation (Figure 10(c)) is the smallest among all the cases studied. The thermal extraction is limited to around the injection wells due to the low reservoir permeability. Figure 10(d) shows the case with the most complete heat energy depletion in the reservoir for Case 4, which was primarily contributed from the development of two parallel manifolds as injector zone and producer zone separately. The reservoir between the injection wells and the production wells has been cooled both significantly and uniformly - the rock temperature has been cooled to the temperature of injected water. This cooling response reinforces the results for the largest heat generation from Case 4. If one set of fractures is less able to slip, then the cooling area as shown in Figure 6(e) would be less than the area in Figure 6(d).

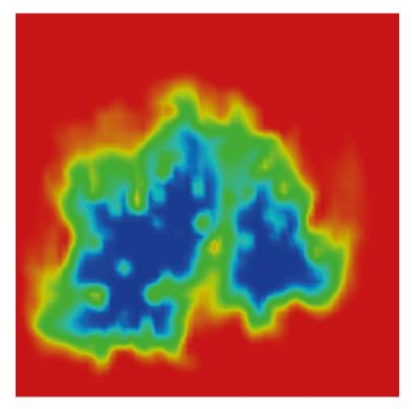

(a)

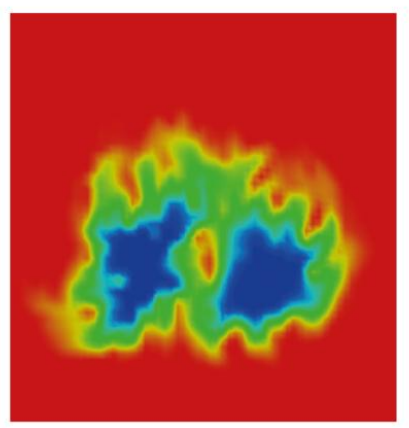

(c)

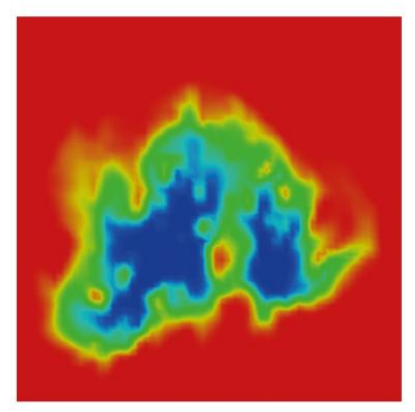

(b)

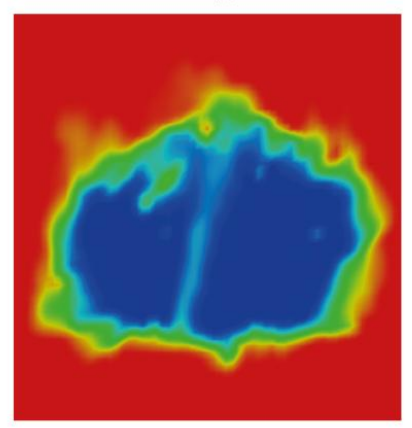

(d)

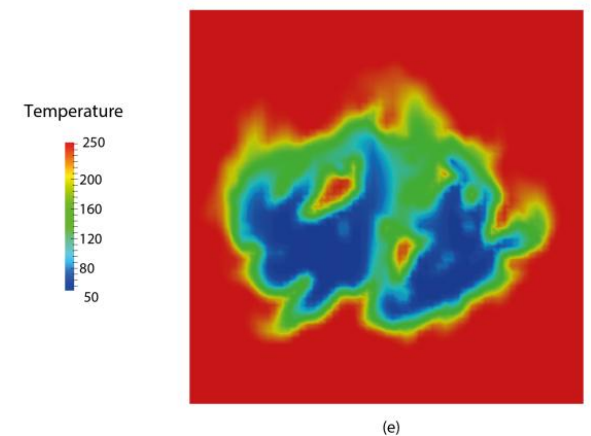


Figure 10. Contour of rock temperature distribution at $t=6.34$ years. (a) Case 1 fracture orientations $020-$ 135 degrees after E-W stimulation, (b) Case 2 fracture orientations 020 - 135 degrees after N-S stimulation, (c) Case 3 without stimulation, (d) Case 4 fracture orientations 045 - 120 degrees after E-W stimulation, (e) Case 5 fracture orientations $045-120$ degrees with friction angle 035 - 75 degrees after E-W stimulation.

\section{Conclusions}

The previous case studies focus on examining the impact of fracture orientation, stimulation strategy, and the fracture density in enhancing the permeability and heat energy extraction from geothermal reservoirs. The best production optimization strategy is obtained from a series of simulations aimed to enhance both the magnitude and longevity of thermal recovery rates.

Reservoir stimulation is demonstrated to be efficient in significantly enhancing the generated power, compared against the results without stimulation. In this study, the eventual production schedule is designed to generate a fluid sweep path in the direction of the minor principal stress (N-S direction). The best optimization that results in the highest power generation is to create two parallel permeable manifolds along the major principal stress direction - in the example here, in the E-W direction. The parallel manifolds become hydraulically interconnected along the axis of the horizontal injection wells in the E-W direction, which are analogous to horizontal wells that allow a uniform sweep of fluids between the zones. The long term production results verify that the manifolds return an improved heat sweep efficiency. Furthermore, the fracture orientation is either very important in influencing the stimulation result. Fractures oriented at 045120 degrees result in the greatest fracture permeability enhancement along the stimulation direction. Therefore, the developed manifolds with fractures oriented at 045120 degrees are more permeable and conductive, compared to the case with fractures oriented at 020-135 degrees.

\section{Acknowledgement}

This work is a partial result of support from the US Department of Energy under project DOE-DE-343 EE0002761. This support is gratefully acknowledged. The authors would 
like to thank the anonymous reviewers for their valuable comments and suggestions to improve the quality of the paper.

\section{Reference}

Akın, S., Kok, M. V., \& Uraz, I. (2010). Optimization of well placement geothermal reservoirs using artificial intelligence. Computers \& Geosciences,36(6), 776-785.

Baghbanan, A., and L. Jing (2007), Hydraulic properties of fractured rock masses with correlated fracture length and aperture, International Journal of Rock Mechanics and Mining Sciences, 44(5), 704-719, doi:http://dx.doi.org/10.1016/j.ijrmms.2006.11.001.

Bandis, S. C., A. C. Lumsden, and N. R. Barton (1983), Fundamentals of rock joint deformation, International Journal of Rock Mechanics and Mining Sciences \& Geomechanics Abstracts, 20(6), 249-268, doi:http://dx.doi.org/10.1016/0148-9062(83)90595-8.

Barton, N., and V. Choubey (1977), The shear strength of rock joints in theory and practice, Rock Mechanics, 10(1-2), 1-54, doi:10.1007/BF01261801.

Crouch, S. L., and A. M. Starfield (1991), Bound Elem Solid Mechanics, Taylor \& Francis. de Dreuzy, J.-R., P. Davy, and O. Bour (2001), Hydraulic properties of two-dimensional random fracture networks following a power law length distribution: 2. Permeability of networks based on lognormal distribution of apertures, Water Resources Research, 37, 2079-2095.

Darnet, M., Marquis, G., \& Sailhac, P. (2006). Hydraulic stimulation of geothermal reservoirs: fluid flow, electric potential and microseismicity relationships. Geophysical Journal International, $166(1), 438-444$.

Dieterich, J. H. (1992), Earthquake nucleation on faults with rate-and state-dependent strength, Tectonophysics, 211(1-4), 115-134, doi:http://dx.doi.org/10.1016/0040-1951(92)90055-B.

Elsworth, D. (1989), Thermal recovery from a multiple stimulated HDR reservoir, Geothermics, 18(5), 761-774.

Elsworth, D. (1990), A comparative evaluation of the parallel flow and spherical reservoir models of HDR geothermal systems, Journal of Volcanology and Geothermal Research, 44(3), 283-293.

Elsworth, D., J. Taron, I. Faoro, D.-S. Lee, J. Liu, A. Niemeijer, and H. Yasuhara (2010),

Evolution of Deformability and Transport Properties of Fractured Rocks Under the Action of Stress and Chemistry, paper presented at EGU General Assembly Conference Abstracts.

Gan, Q., and D. Elsworth (2014a), Analysis of fluid injection - induced fault reactivation and seismic slip in geothermal reservoirs, Journal of Geophysical Research: Solid Earth, 119(4), 3340-3353. 
Gan, Q., and D. Elsworth (2014b), Thermal drawdown and late-stage seismic-slip fault reactivation in enhanced geothermal reservoirs, J. Geophys. Res. Solid Earth, 119, 8936-8949, doi:10.1002/2014JB011323.

Gan, Q., and D. Elsworth (2016), "A continuum model for coupled stress and fluid flow in discrete fracture networks." Geomechanics and Geophysics for Geo-Energy and Geo-Resources: $1-19$.

Ghassemi, A., and Q. Zhang (2006), Porothermoelastic analysis of the response of a stationary crack using the displacement discontinuity method, Journal of engineering mechanics, 132(1), 26-33.

Gringarten, A., and P. Witherspoon (1973), Extraction of heat from multiple-fractured dry hot rock, Geothermics, 2(3), 119-122.

Gringarten, A., P. Witherspoon, and Y. Ohnishi (1975), Theory of heat extraction from fractured hot dry rock, Journal of Geophysical Research, 80(8), 1120-1124.

Marcou, J. A. (1985). Optimizing development strategy for liquid dominated geothermal reservoirs (Doctoral dissertation, Stanford University).

McClure, M., and R. N. Horne (2013), Discrete fracture network modeling of hydraulic stimulation: Coupling flow and geomechanics, Springer Science \& Business Media.

Min, K.-B., and L. Jing (2003), Numerical determination of the equivalent elastic compliance tensor for fractured rock masses using the distinct element method, International Journal of Rock Mechanics and Mining Sciences, 40(6), 795-816.

Oda, M. (1986), An equivalent continuum model for coupled stress and fluid flow analysis in jointed rock masses, Water Resources Research, 22(13), 1845-1856,

doi:10.1029/WR022i013p01845.

Odling, N. E., Gillespie, P., Bourgine, B., Castaing, C., Chiles, J. P., Christensen, N. P., \&

Watterson, J. (1999). Variations in fracture system geometry and their implications for fluid flow in fractured hydrocarbon reservoirs. Petroleum Geoscience, 5(4), 373-384.

Olson, J. E. (2003), Sublinear scaling of fracture aperture versus length: an exception or the rule?, Journal of Geophysical Research: Solid Earth (1978-2012), 108(B9).

Pham, M., Ponte, C. K. C., Cabeças, R., Martins, R., \& Rangel, G. (2010). Production/Injection

Optimization Using Numerical Modeling at Ribeira Grande, São Miguel, Azores, Portugal. In Proc. World Geothermal Congress 2010.

Pine, R. J., \& Cundall, P. A. (1985). Applications of the fluid-rock interaction program (FRIP) to the modelling of hot dry rock geothermal energy systems. In Proc. Int. Symp. on Fundamentals of Rock Joints (pp. 293-302). Centek. 
Pruess, K. (2006), Enhanced geothermal systems (EGS) using CO 2 as working fluid - a novel approach for generating renewable energy with simultaneous sequestration of carbon, Geothermics, 35(4), 351-367.

Pruess, K., and Y.-S. Wu (1993), A new semi-analytical method for numerical simulation of fluid and heat flow in fractured reservoirs, SPE Advanced Technology Series, 1(2), 63-72.

Riahi, A., \& Damjanac, B. (2013, February). Numerical study of hydro-shearing in geothermal reservoirs with a pre-existing discrete fracture network. InProceedings of the 38th Workshop on Geothermal Reservoir Engineering, Stanford, CA (pp. 11-13).

Rutqvist, J., Leung, C., Hoch, A., Wang, Y., \& Wang, Z. (2013). Linked multicontinuum and crack tensor approach for modeling of coupled geomechanics, fluid flow and transport in fractured rock. Journal of Rock Mechanics and Geotechnical Engineering, 5(1), 18-31.

Sanyal, S. K., and S. J. Butler (2005), An analysis of power generation prospects from enhanced geothermal systems, Geothermal Resources Council Transactions, 29.

Sanyal, S. K., E. E. Granados, S. J. Butler, and R. N. Horne (2005), An alternative and modular approach to enhanced geothermal systems, paper presented at World Geothermal Congress. Segall, P., and S. D. Fitzgerald (1998), A note on induced stress changes in hydrocarbon and geothermal reservoirs, Tectonophysics, 289(1-3), 117-128, doi:http://dx.doi.org/10.1016/S00401951(97)00311-9.

Shaik, A. R., S. S. Rahman, N. H. Tran, and T. Tran (2011), Numerical simulation of fluid-rock coupling heat transfer in naturally fractured geothermal system, Applied thermal engineering, 31(10), 1600-1606.

Taron, J., and D. Elsworth (2009), Thermal-hydrologic-mechanical-chemical processes in the evolution of engineered geothermal reservoirs, International Journal of Rock Mechanics and Mining Sciences, 46(5), 855-864.

Taron, J., and D. Elsworth (2010a), Constraints on compaction rate and equilibrium in the pressure solution creep of quartz aggregates and fractures: Controls of aqueous concentration, Journal of Geophysical Research: Solid Earth (1978-2012), 115(B7).

Taron, J., and D. Elsworth (2010b), Coupled mechanical and chemical processes in engineered geothermal reservoirs with dynamic permeability, International Journal of Rock Mechanics and Mining Sciences, 47(8), 1339-1348.

Tester, J. W., B. Anderson, A. Batchelor, D. Blackwell, R. DiPippo, E. Drake, J. Garnish, B. Livesay, M. C. Moore, and K. Nichols (2006), The future of geothermal energy: Impact of enhanced geothermal systems (EGS) on the United States in the 21st century, Massachusetts Institute of Technology, 209. 
Vörös, R., R. Weidler, L. de Graaf, and D. Wyborn (2007), THERMAL MODELLING OF LONG TERM CIRCULATION OF MULTI-WELL DEVELOPMENT AT THE COOPER BASIN HOT FRACTURED ROCK (HFR) PROJECT AND CURRENT PROPOSED SCALEUP PROGRAM, paper presented at Proceedings of the Thirty-Second Workshop on Geothermal Reservoir Engineering, Stanford, CA, USA.

Watanabe, K., Y. Niibori, and T. Hashida (2000), Numerical study on heat extraction from supercritical geothermal reservoir, paper presented at Proceedings World Geothermal Congress. 


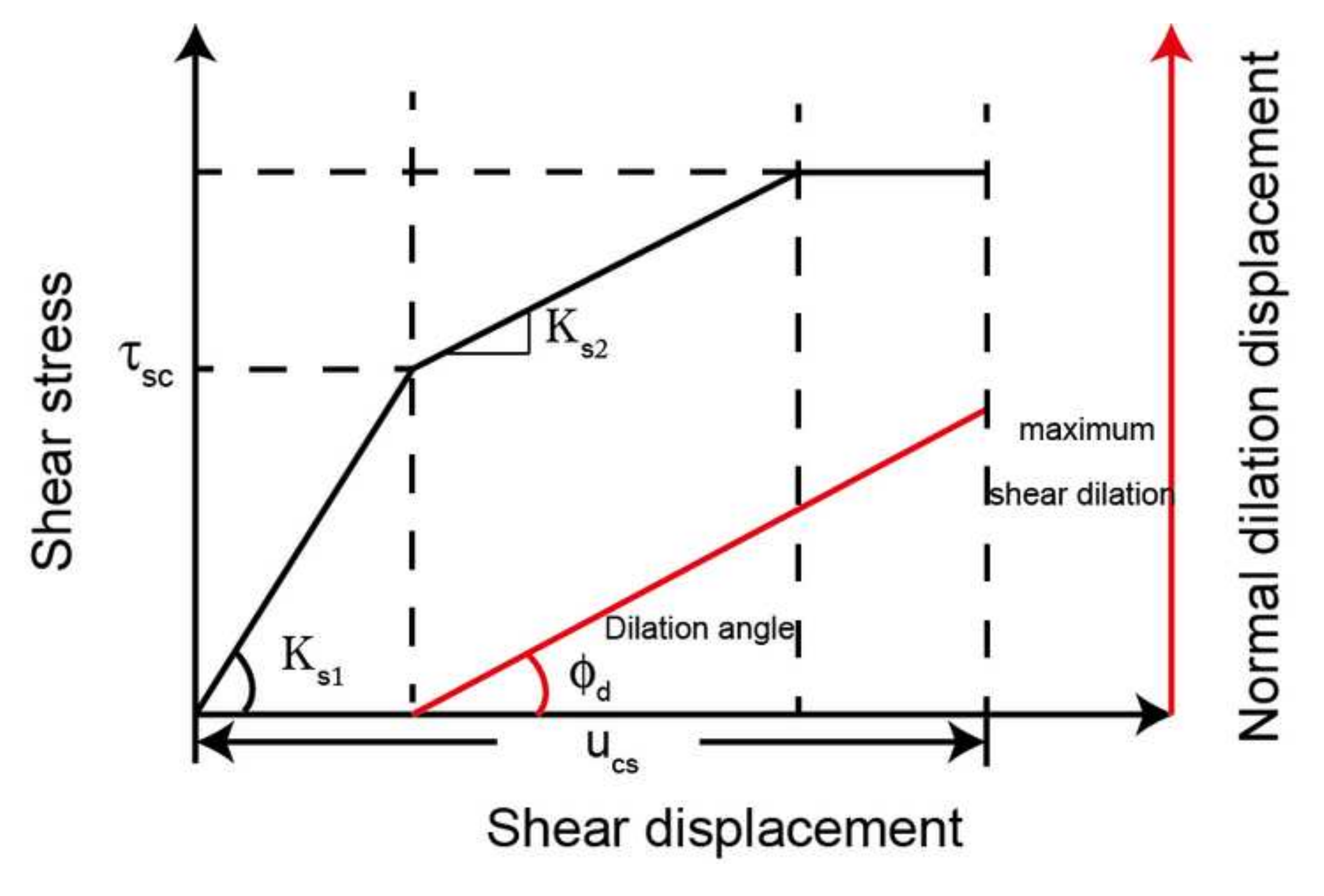

Shear displacement 


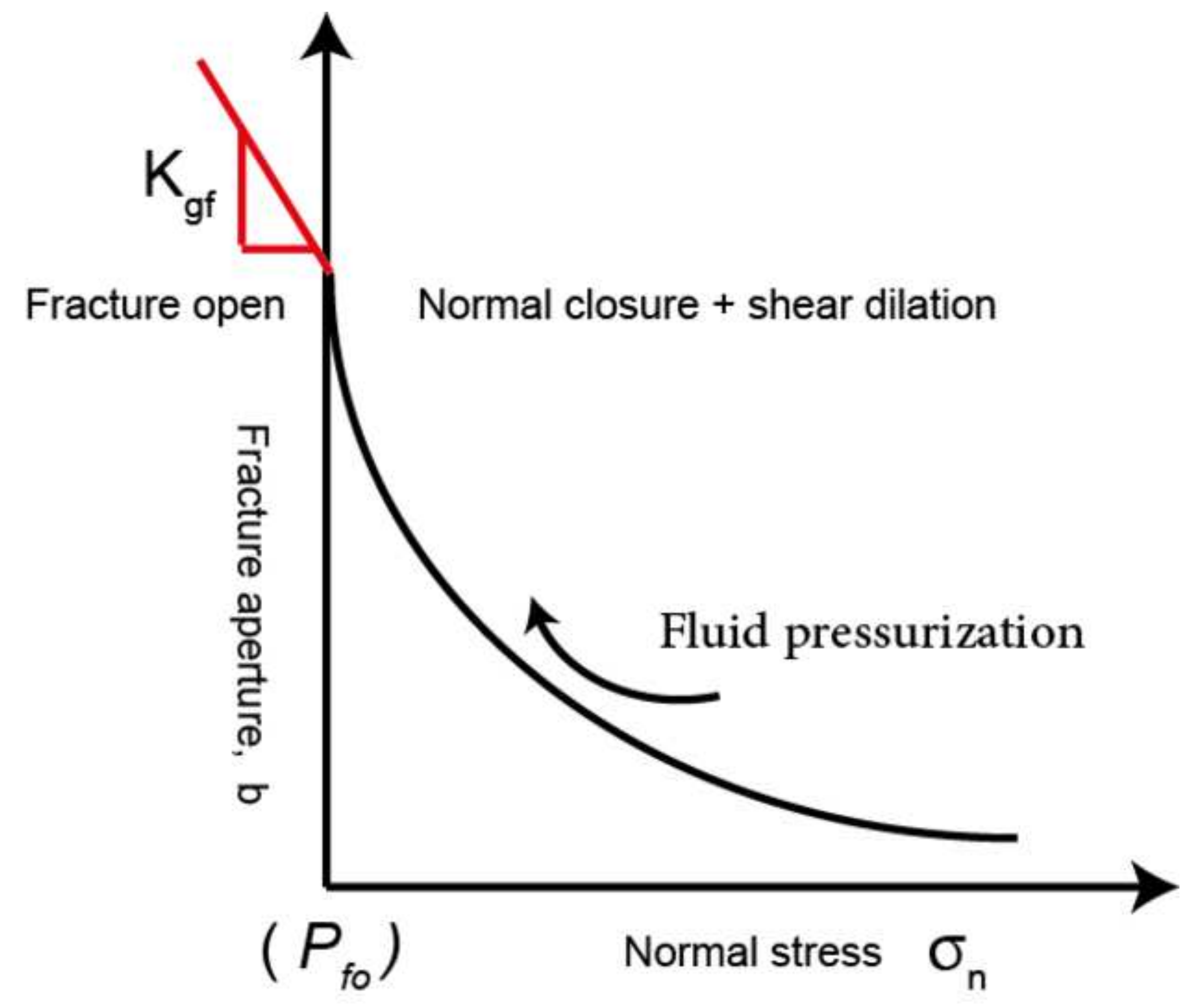

Fracture open

Normal closure + shear dilation

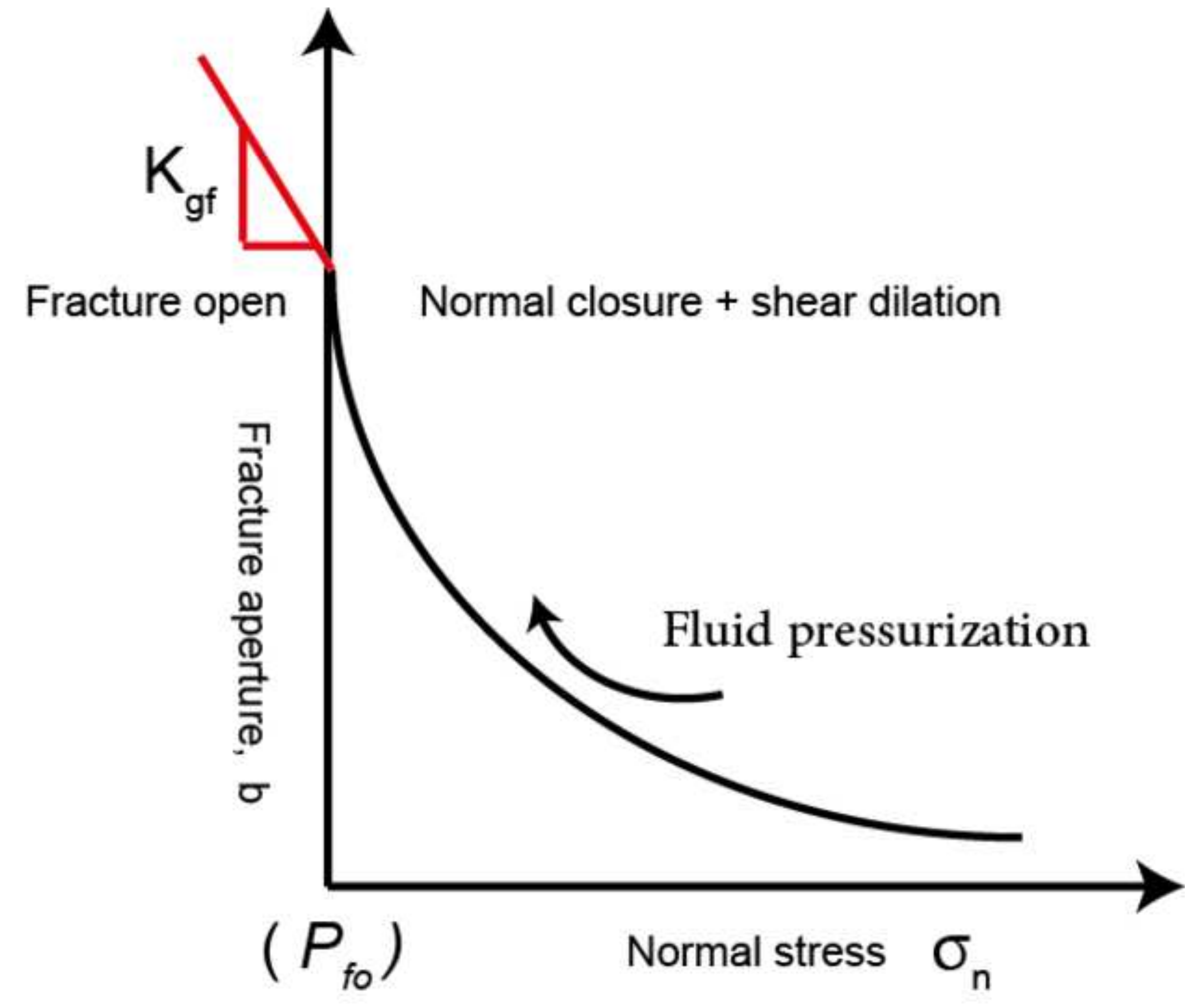




\section{E-W stimulation}

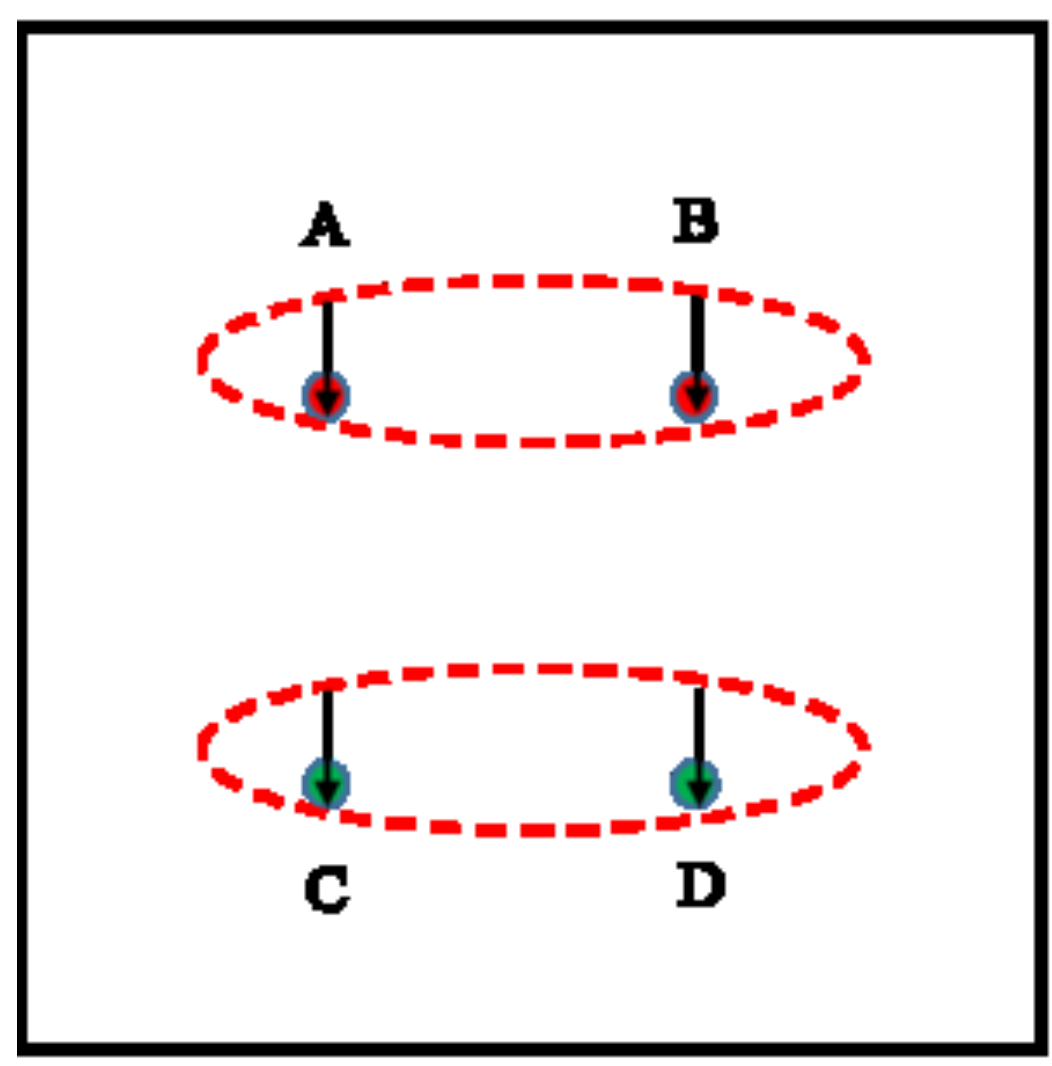

(a)
$\mathbf{N}-\mathbf{S}$ stimmlation

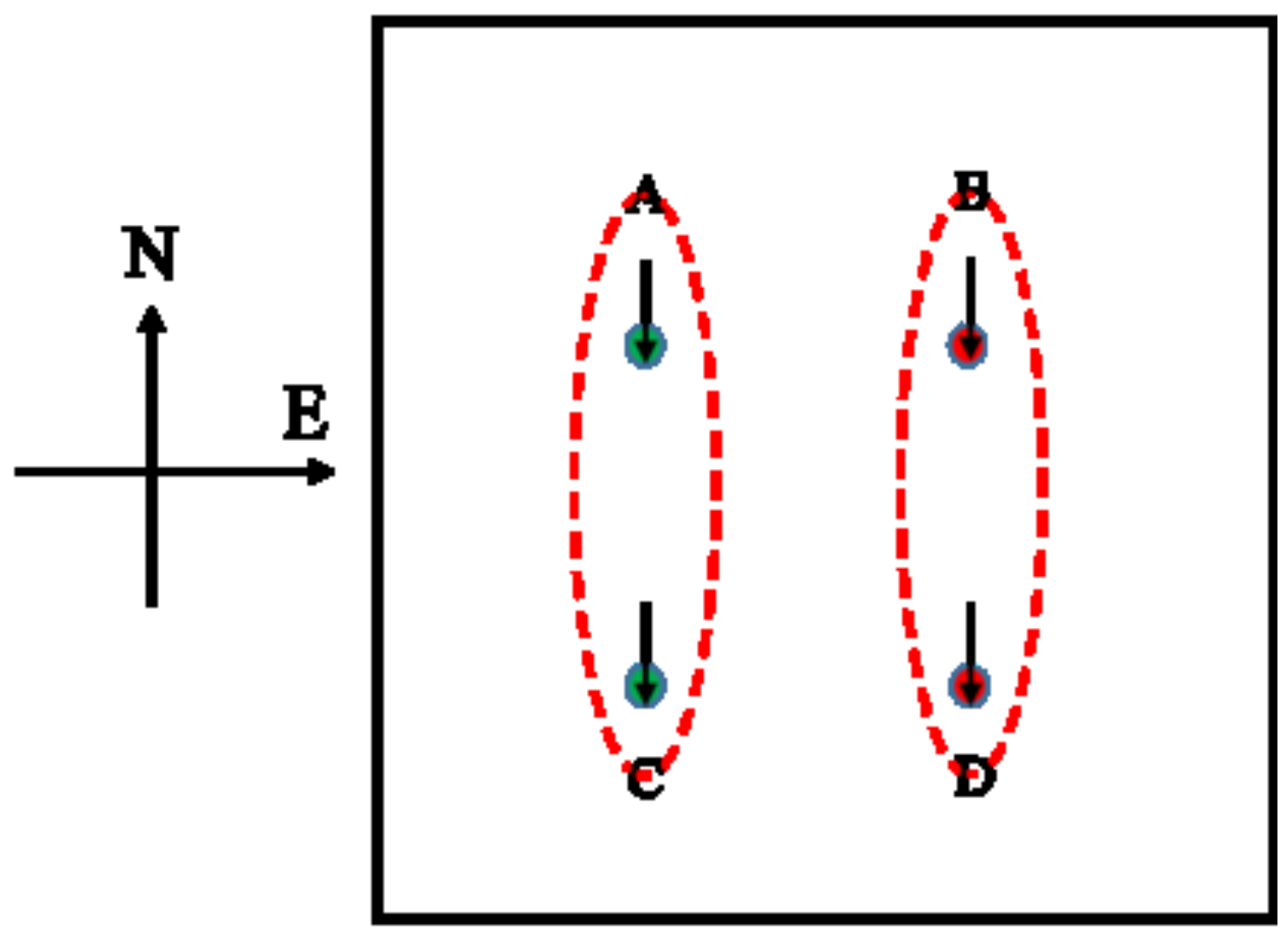

(b) 


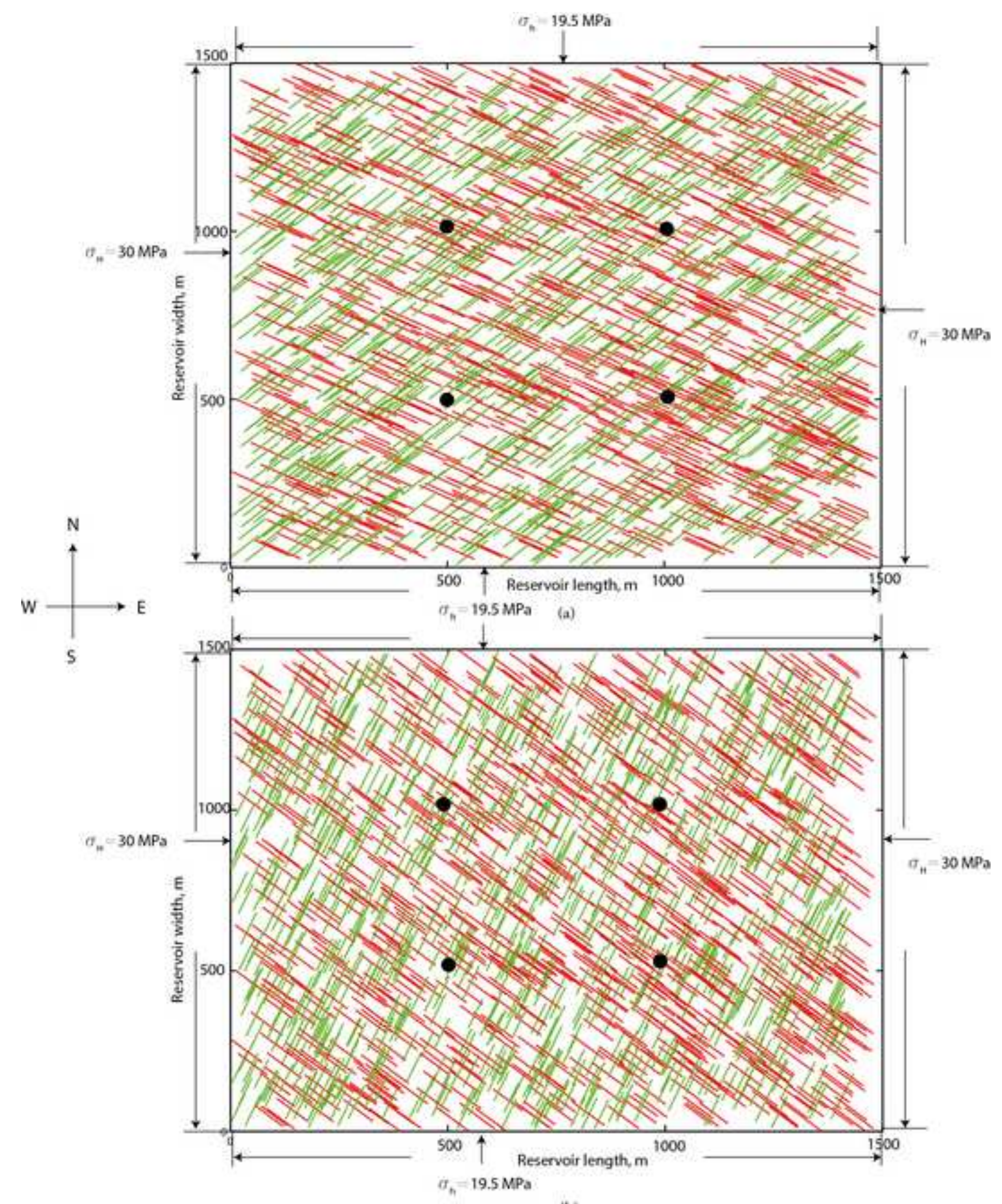

(b) 


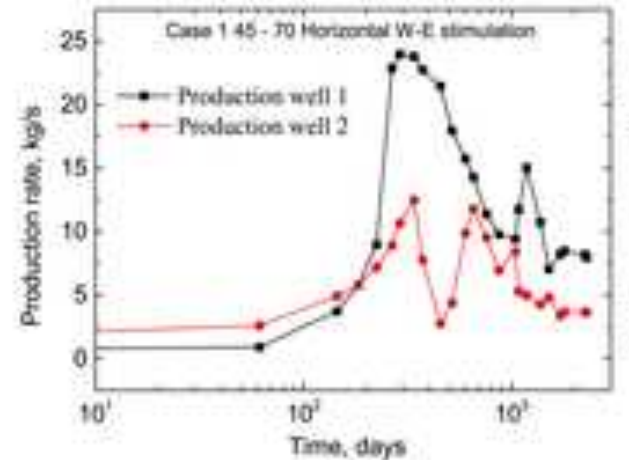

(a)
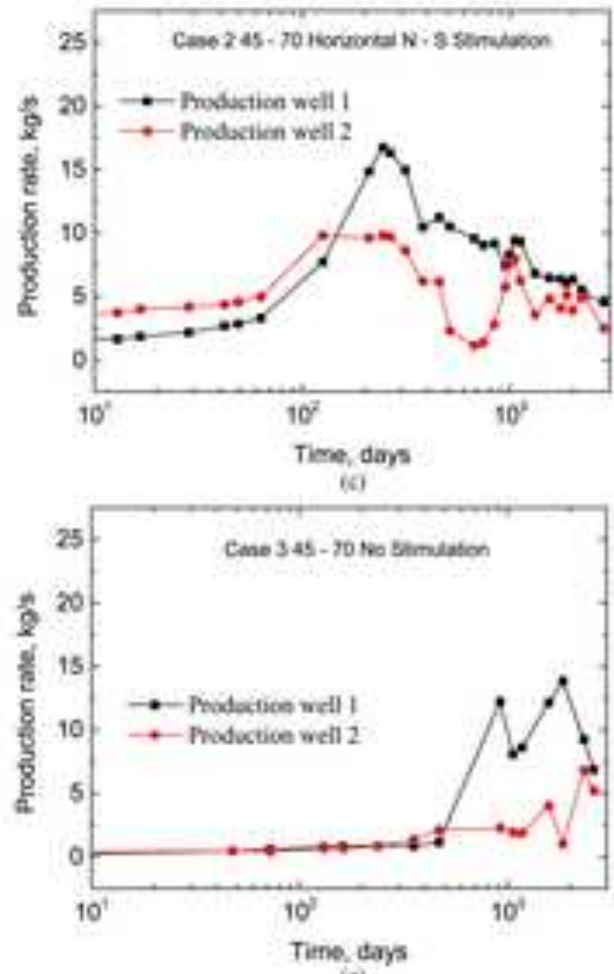

iel
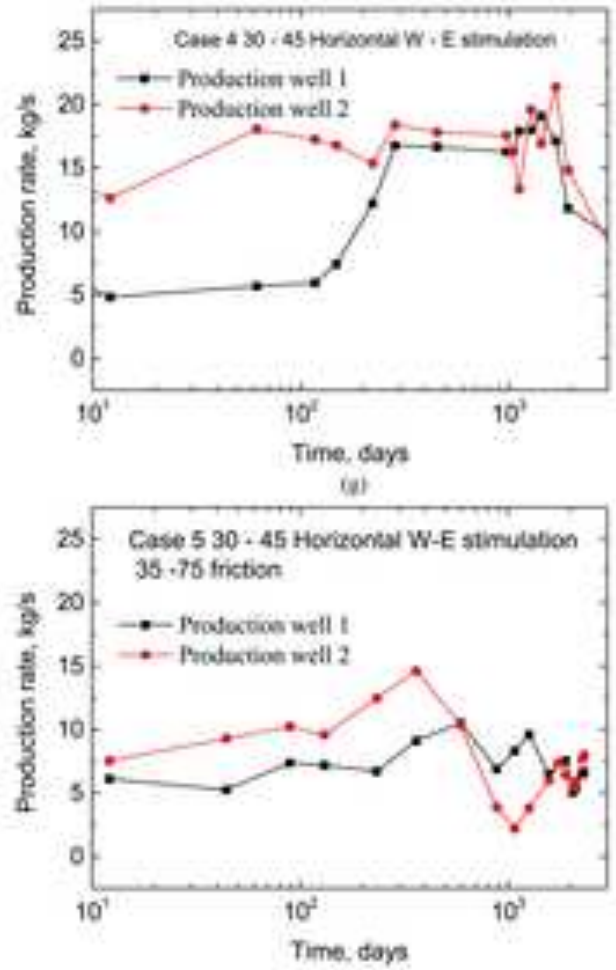

(ii)

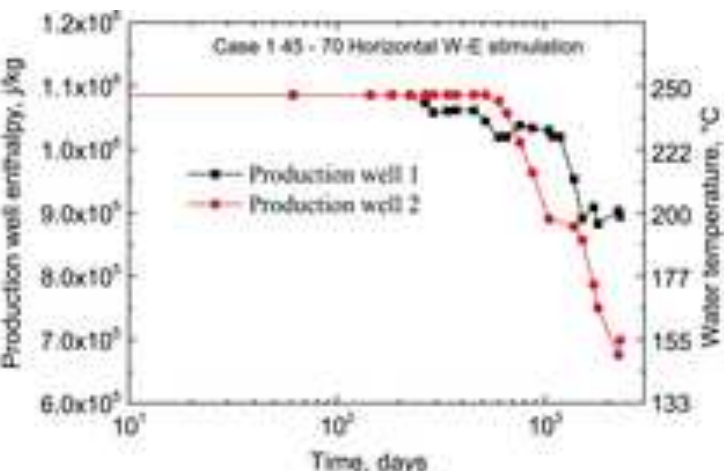

(b)
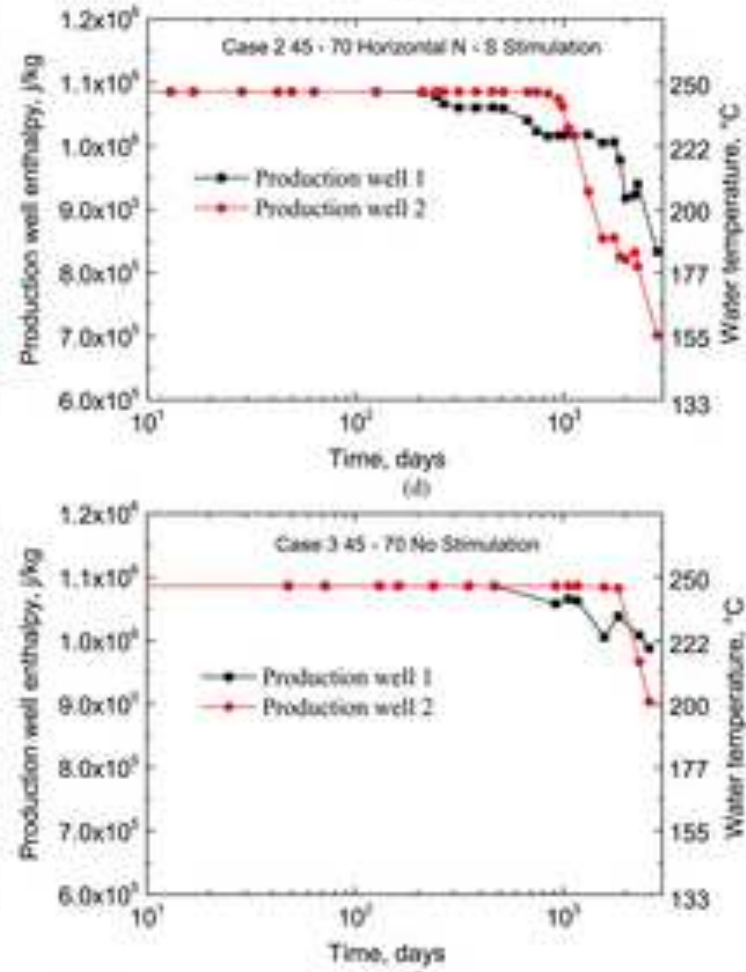

(i)

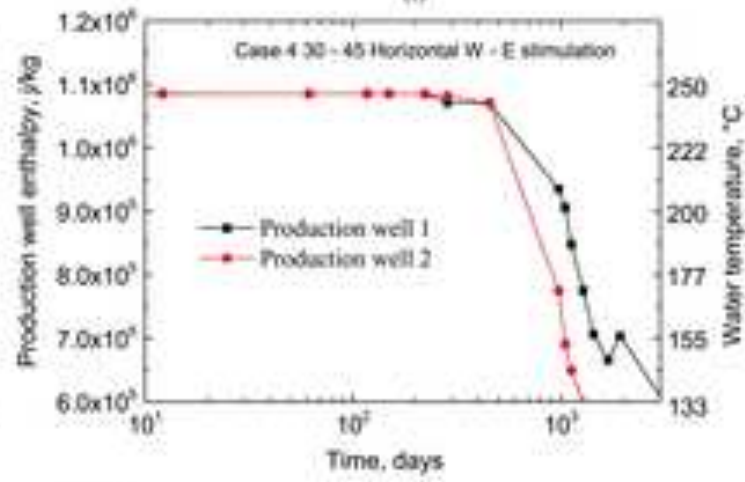

(i)

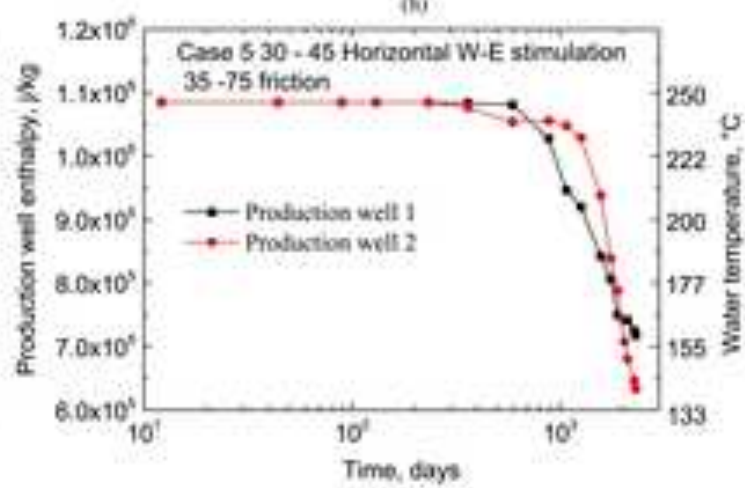

(ii) 
Horizontal E-W Stimulation

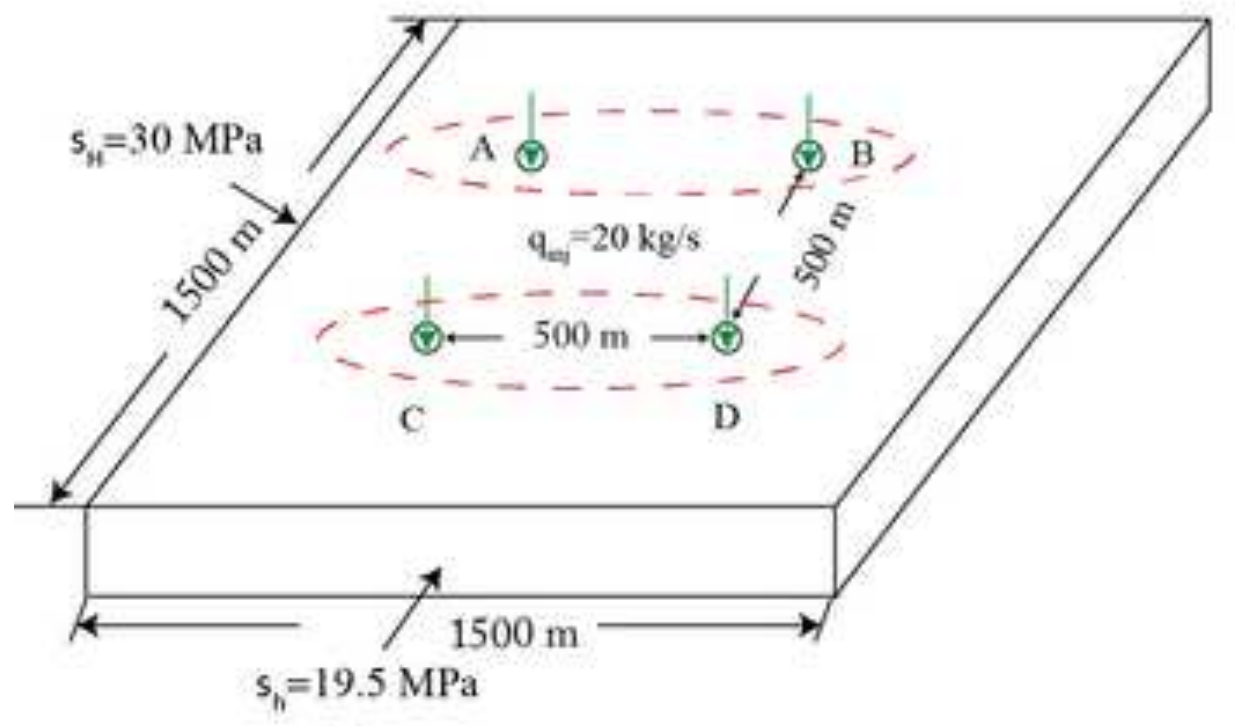

(a)

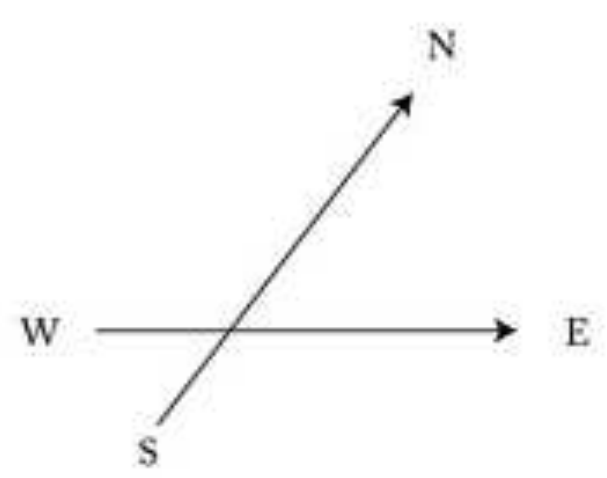

\section{Horizontal N-S Stimulation}

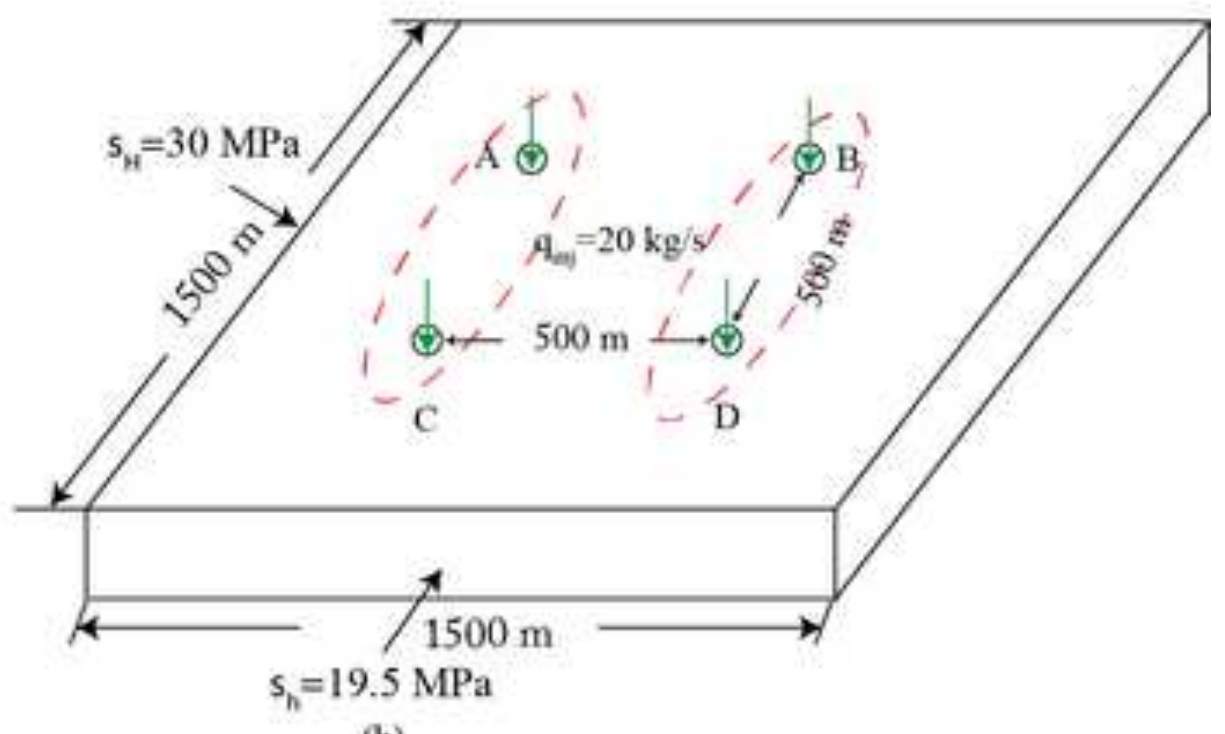

(b)

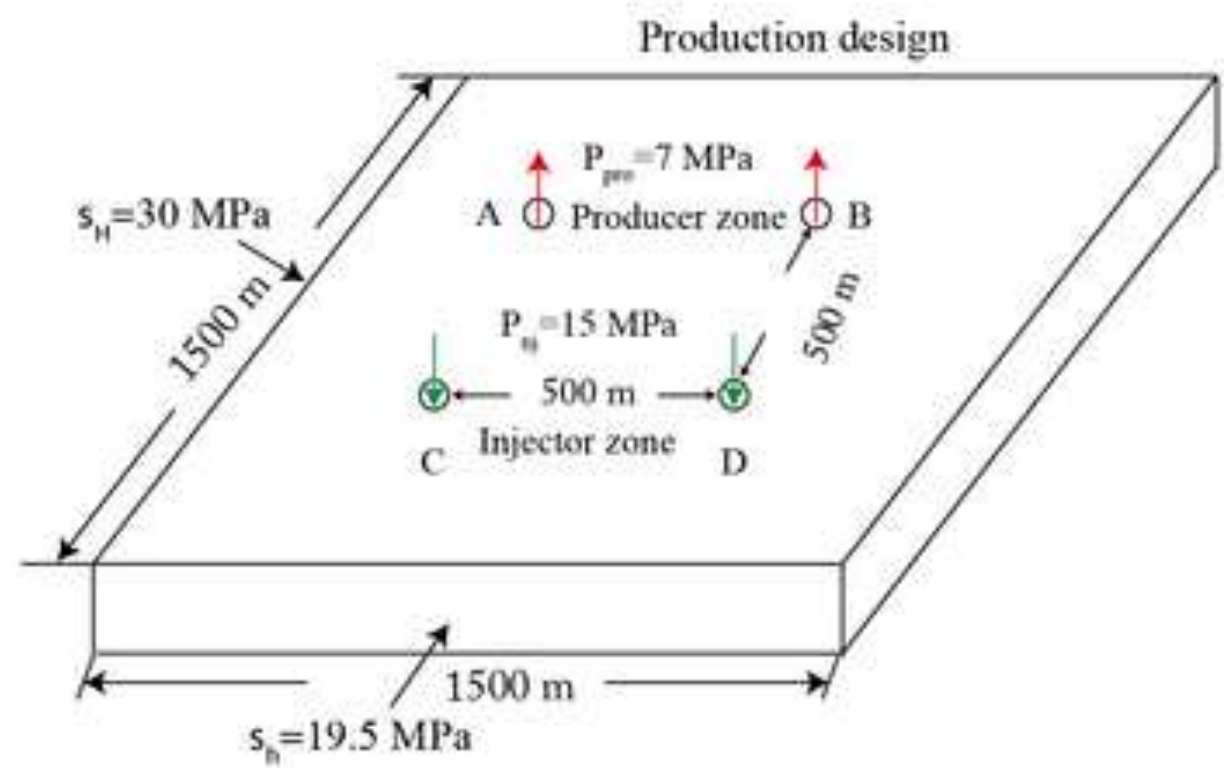

(c) 


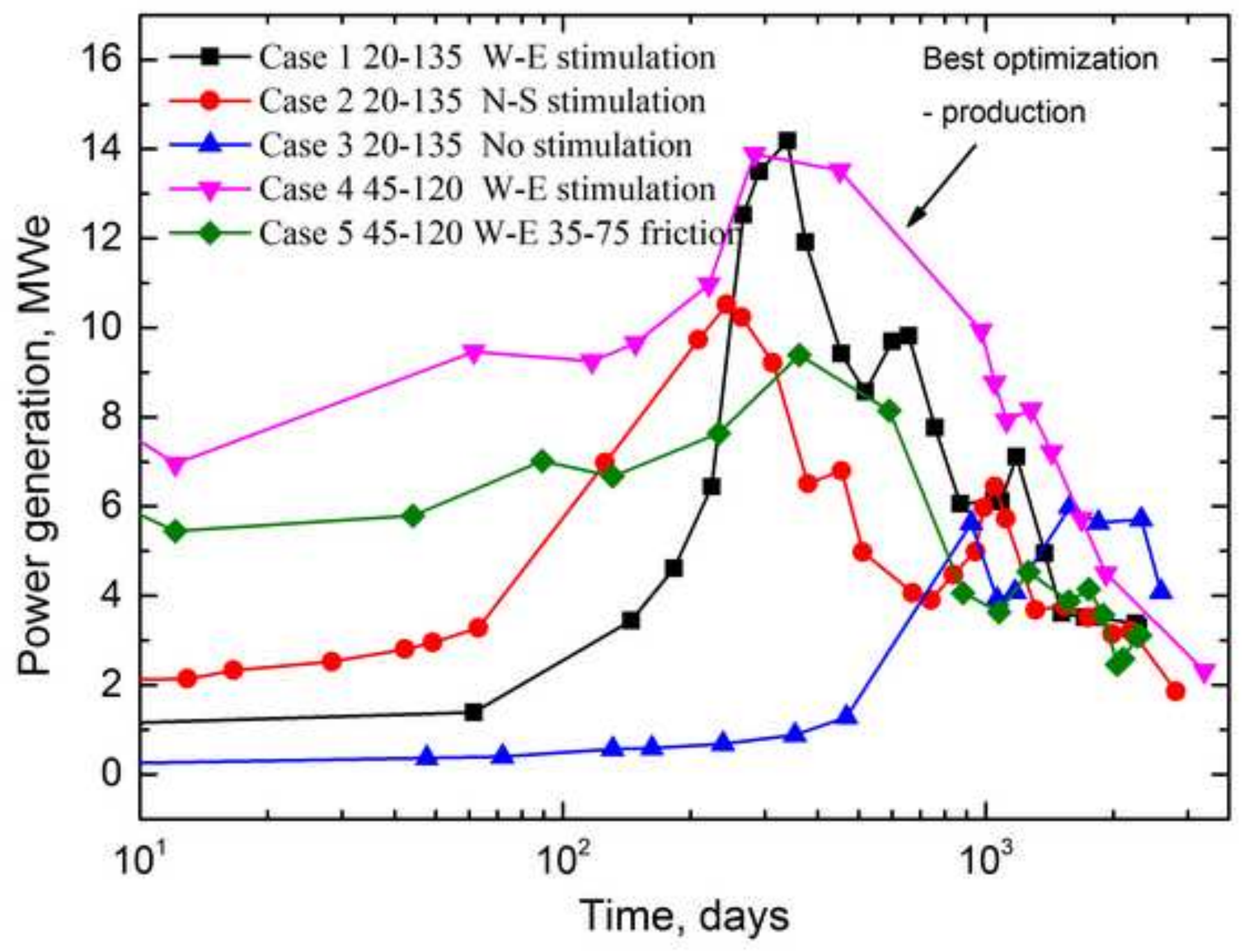


Figure 9
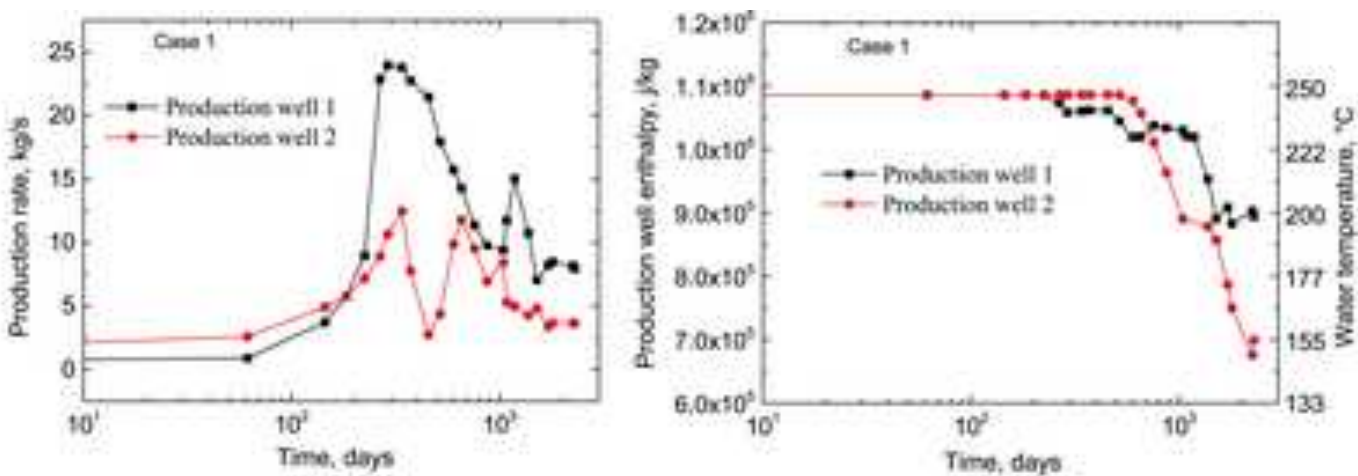

(i)
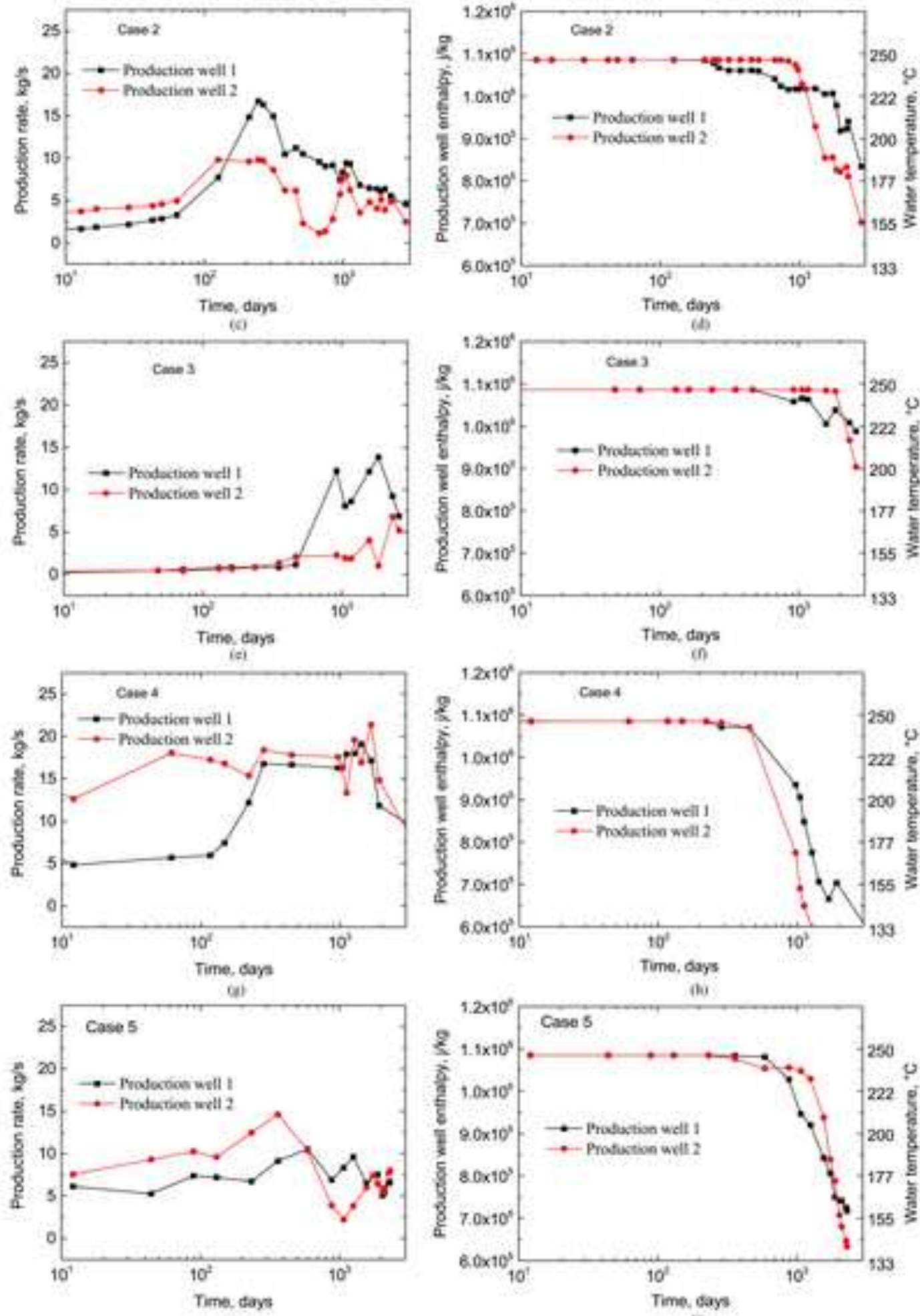

(ii)

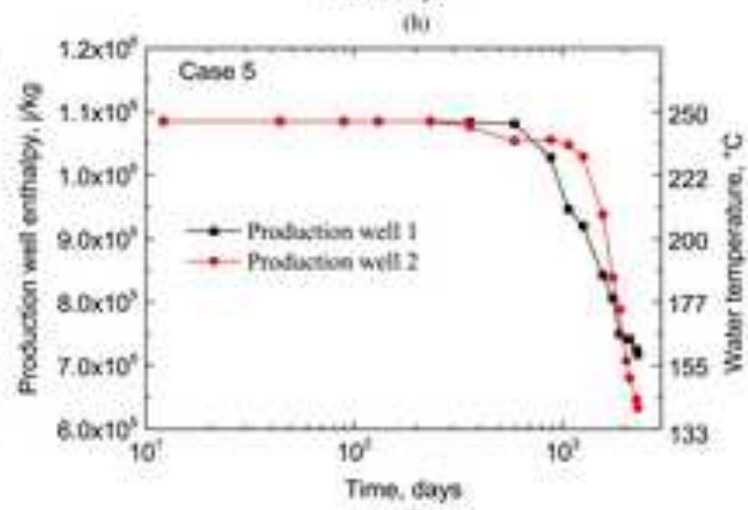

(ii) 


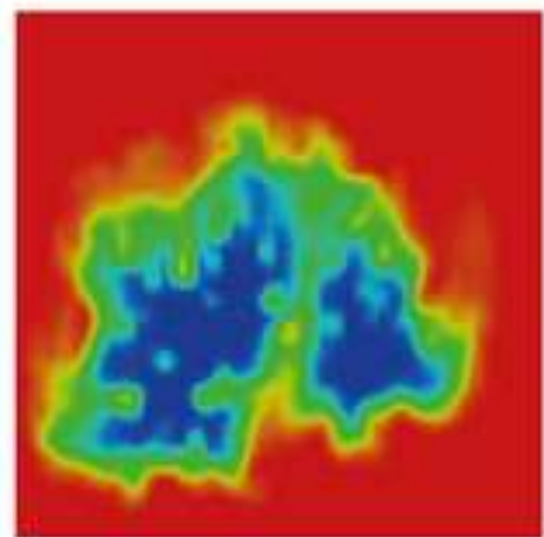

(a)

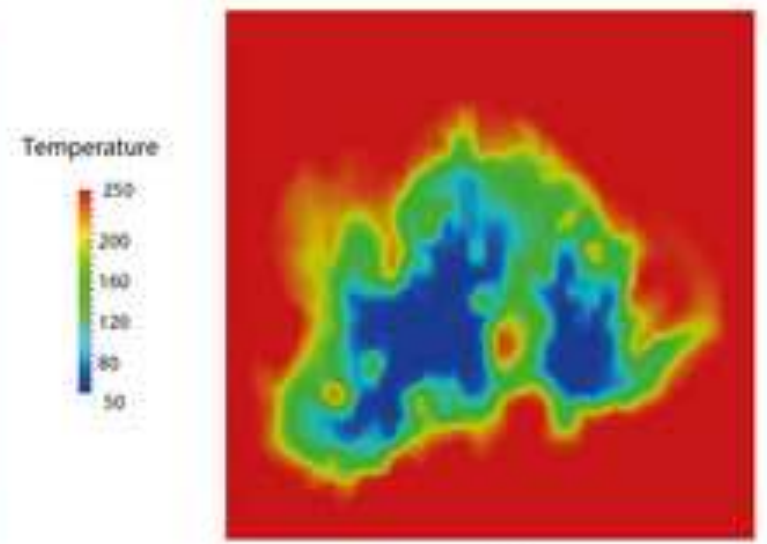

abs

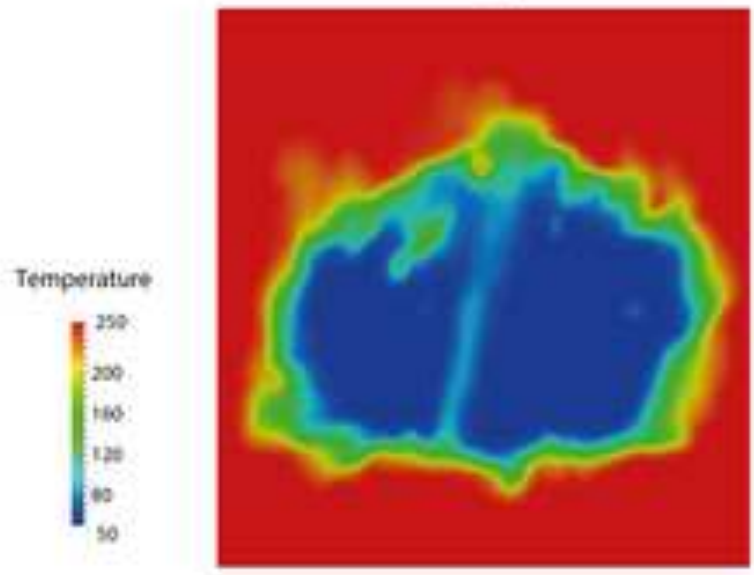

is

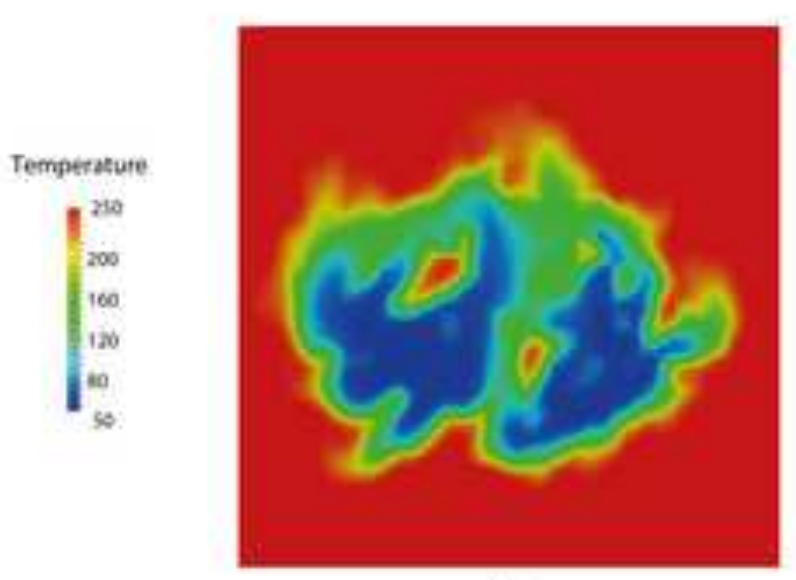

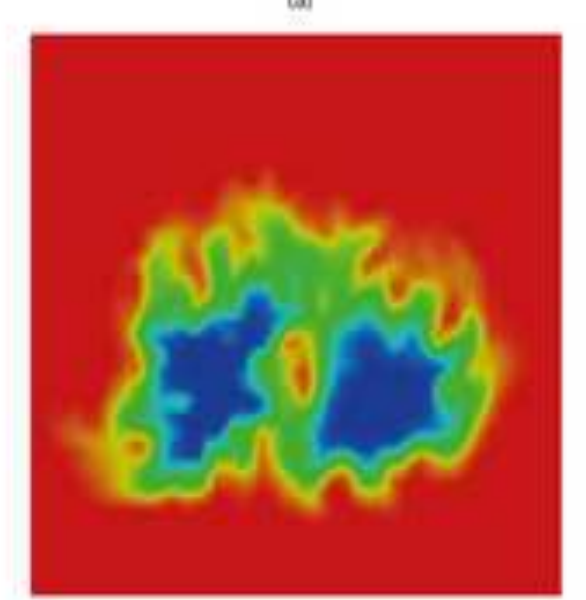

is

$\left.\right|_{58} ^{200}$ 